\title{
Assessing demographic access to hip replacement surgery in the United Kingdom: a systematic review
}

\author{
Sebastian Ryan-Ndegwa', Reza Zamani ${ }^{1}$ and Mohammad Akrami ${ }^{2^{*}}$ (D)
}

\begin{abstract}
Persisting evidence suggests significant socioeconomic and sociodemographic inequalities in access to medical treatment in the UK. Consequently, a systematic review was undertaken to examine these access inequalities in relation to hip replacement surgery. Database searches were performed using MEDLINE, PubMed and Web of Science. Studies with a focus on surgical need, access, provision and outcome were of interest. Inequalities were explored in the context of sociodemographic characteristics, socioeconomic status (SES), geographical location and hospital-related variables. Only studies in the context of the UK were included. Screening of search and extraction of data were performed and 482 articles were identified in the database search, of which 16 were eligible. Eligible studies consisted of eight cross-sectional studies, seven ecological studies and one longitudinal study. Although socioeconomic inequality has somewhat decreased, lower SES patients and ethnic minority patients demonstrate increased surgical needs, reduced access and poor outcomes. Lower SES and Black minority patients were younger and had more comorbidities. Surgical need increased with age. Women had greater surgical need and provision than men. Geographical inequality had reduced in Scotland, but a north-south divide persists in England. Rural areas received greater provision relative to need, despite increased travel for care. In all, access inequalities remain widespread and policy change driven by research is needed.
\end{abstract}

Keywords: Hip replacement surgery, Demographic access, United Kingdom, Systematic review

\section{Introduction}

A key tenet of the United Kingdom's National Health Service (NHS) is that access to healthcare should be fair and equal for all [1]. Whilst direct financial barriers to healthcare are mostly absorbed by the NHS in the UK [2], barriers presented by indirect and intangible costs still persist. Studies dating back to 1968 [3] report significant socioeconomic and sociodemographic inequalities in access to medical treatment. These inequalities have endured through time, with those of higher

\footnotetext{
*Correspondence: m.akrami@exeter.ac.uk

${ }^{2}$ Department of Engineering, College of Engineering, Mathematics, and Physical Sciences, University of Exeter, Exeter, UK

Full list of author information is available at the end of the article
}

socioeconomic status (SES) still receiving better surgical provisions and outcomes relative to need [1]. Inequalities faced by ethnic minorities need to be acknowledged as they have poorer access relative to White patients [4]. A recent review [5] also highlighted ethnic minority patients' increased vulnerability to patient safety events, including surgical complications and hospital-acquired infections. Since 2010, government spending on critical social determinants of health has declined by $7 \%$ [6]. These reductions have disproportionately impacted the clinical commissioning groups (CCG) responsible for ensuring access to healthcare for the most deprived communities of the UK. Consequently, there is a need to determine which patients face the greatest inequalities to help CCGs plan how to distribute their limited financial original author(s) and the source, provide a link to the Creative Commons licence, and indicate if changes were made. The images or other third party material in this article are included in the article's Creative Commons licence, unless indicated otherwise in a credit line to the material. If material is not included in the article's Creative Commons licence and your intended use is not permitted by statutory regulation or exceeds the permitted use, you will need to obtain permission directly from the copyright holder. To view a copy of this licence, visit http://creativecommons.org/licenses/by/4.0/. The Creative Commons Public Domain Dedication waiver (http://creativeco mmons.org/publicdomain/zero/1.0/) applies to the data made available in this article, unless otherwise stated in a credit line to the data. 
resources to those in greatest need. Hip replacement is one of the most frequently performed surgeries in the UK [7], making it a strong case for exploring access inequalities. Hip replacement is cost-effective [8] and improves the quality of life of elderly patients [9]. Given the ageing population of the UK [10], the healthcare burden placed on the NHS is growing. In 2015, it was predicted that the NHS will need to conduct an estimated 439,097 hip replacement surgeries by 2035 [11]. In addition to this figure, almost 100,000 patients are waiting for delayed joint replacement surgery due to COVID-19 [12]. Upper estimates from the British Medical Association suggest that clearing the backlog of elective surgery will cost the NHS $£ 5.4$ billion [13]. Delayed hip replacements have a detrimental impact on patients [14], including worse postoperative outcomes, depression [15] and increased reliance on opioid painkillers [16]. The direct and indirect costs associated with delayed surgery increase the financial strain on patients and the NHS [14]. The NHS Long Term Plan [17] aims to improve healthcare access, with an estimated $£ 1$ billion spend in areas with the greatest inequalities. Previous financial incentives to promote healthcare equality, such as 'pay-for-performance' schemes have been criticised for their inability to tackle 'pro-rich' inequalities in hip replacement surgery [18]. Furthermore, evidence suggests that adding this competitive element to healthcare, leads to a fading of ethics in how performance goals are achieved [19]. This 'ethical fading' in the pursuit of achieving greater funding, risks exacerbating inequalities in the social determinants of health. By providing a breakdown of factors affecting access to hip replacement surgery, this systematic review aims to provide evidence to inform policy decisions. The objectives will be to: 1 ) determine which patients experience inequalities in access to hip replacement surgery; 2) determine where these patients are located in the UK and 3) explore other variables that influence the observations, such as differences between hospitals. This review will take a multi-faceted approach by exploring surgical access, need, provision and outcome to achieve a wider picture of which areas drive access inequalities. Inequalities in healthcare access have been reviewed previously [20], but no review has focused explicitly on hip replacement surgery. A PhD thesis [21] containing a systematic review exploring equality in access was identified. However, the scope differed from this review as it included multiple countries and knee replacement surgery.

\section{Methods}

A systematic search of published literature was performed on 4th February 2021. The search strategy followed the Population, Phenomena of Interest and Context (PICo) framework (Table 1).

PICo is explicitly designed [22] for qualitative research and is adapted from the Population, Intervention, Control, Outcome (PICO) framework. Relevant Medical Subject Headings (MeSH) keywords were extracted from the previous review [21] and organised into PICo subheadings. The search was performed in the following databases: MEDLINE, PubMed and Web of Science. The complete search strategy is described Table 9 in Appendix 1.

\section{Eligibility criteria}

Search records were eligible for inclusion provided specific criteria were met (Table 2). Identified articles were reviewed as specified by the Preferred Reporting Items for Systematic Review and Meta-Analyses (PRISMA) 2020 guidelines [23]. Articles were organised, screened and de-duplicated using Rayyan [24], a semi-automated web-tool that assists with exclusion and inclusion decisions while automatically detecting duplicate studies.

\section{Assessment of risk of bias}

The risk of bias of the included studies was assessed using a checklist adapted from Mújica-Mota et al. [25] This checklist assesses the impact of selection bias and confounding, two significant challenges.

for observational studies [26]. The checklist questions determine patient characteristics, patient wellbeing, disease severity, detail of hip surgery and hospital-related confounders. The presence of confidence intervals was used to determine whether random error was accounted for in study data. A score was calculated as a sum of the criteria met by each study to facilitate comparison between them.

Table 1 Framework for organisation of search strategy

\begin{tabular}{lll}
\hline Population (P) & Interest (I) & Context (Co) \\
\hline $\begin{array}{ll}\text { Hip replacement recipients and individuals in } \\
\text { need of hip replacement surgery }\end{array}$ & $\begin{array}{l}\text { Inequalities in access, need, provision and surgi- } \\
\text { cal outcome }\end{array}$ & $\begin{array}{l}\text { I) Impact of sociodemographic variables, } \\
\text { socioeconomic status, geographical location and } \\
\text { hospital-related variables }\end{array}$ \\
& & II) Study cohorts and data populations located in \\
& & the United Kingdom \\
\hline
\end{tabular}


Table 2 Inclusion and exclusion criteria for included studies

\begin{tabular}{|c|c|}
\hline Inclusion criteria & Exclusion criteria \\
\hline Studies written in English & Non-English language studies \\
\hline Studies with cohorts in England, Scotland, Wales and Northern Ireland & Studies without UK-based cohorts \\
\hline $\begin{array}{l}\text { Studies focusing on total hip replacement or with specific data on total hip } \\
\text { replacement }\end{array}$ & $\begin{array}{l}\text { Studies investigating total hip replacement in combination with } \\
\text { other diseases with no specific data or conclusions based on total hip }\end{array}$ \\
\hline Publications between 16th December 2005 and $2021^{\text {a }}$ & replacement alone \\
\hline Types of studies: any observational study (cross-sectional studies, ecological & Studies published prior to 16 th December $2005^{a}$ \\
\hline studies, case-control studies, longitudinal studies) & Editorials, comments or review articles \\
\hline Peer-reviewed literature & \\
\hline
\end{tabular}

${ }^{a}$ To exclude papers covered by previous review, avoiding repetition of analyses/additional overlaps

\section{Data extraction}

Published data from the included studies were extracted under the following categories: study design, year of publication, study population, study timeframe, source of study data and measurement domains. This data is presented in Table 3 . These categories were adapted from the study overview presented in a previous paper [21].

\section{Results}

Search results

Over the three databases searched (MEDLINE, PubMed and Web of Science), 482 articles were identified, of which 382 were removed in the deduplication process. With duplicates removed, 120 articles were screened against the inclusion criteria. Sixty-six papers published before December 2005 and those without UK-based cohorts were removed. The remaining 54 articles were screened against the exclusion criteria, using full-text copies, resulting in the removal of a further 38 papers. Reasons for removal are shown Figure 1 in Appendix 2. The most prevalent reasons for removal were studies that discussed an unrelated pathology $(n=6)$, such as shoulder arthroplasty, and studies relating to patients' postoperative return to work $(n=6)$. The 16 remaining studies were included in this systematic review.

\section{Study characteristics}

The 16 studies included in this review are of varying characteristics and demographics. Table 3 shows an overview of the study characteristics. The year of publication for the included studies ranged from 2007 to 2016. The largest study [27] explored 406,253 patients over 10 years and the smallest study [28] explored 282 patients over a single year. Of the included studies, 8 were crosssectional studies [1, 2, 28-33], 7 were ecological studies [4, 27, 34-38] and one was a longitudinal study [39]. The shortest timeframe of the included studies was 1 year [2, $28-30,32]$, and the longest was 10 years [27, 31]. The datasets used by studies ranged in age from 1991 [31] to
2012 [4]. In terms of patient-level datasets used, seven studies incorporated Hospital Episode Statistics (HES) data [1, 2, 4, 30-33], an England-wide database of all NHS hospital activity. One study used the Scottish Morbidity Record [36], which provides similar patient-level data to HES, but for Scotland. Four studies used internal hospital data [28, 29, 37, 39] and two studies used unspecified national, patient-level data [27, 38]. Two studies used a combination of local-scale and nationalscale, patient-level data from the Somerset and Avon Survey of Health and the English Longitudinal Study of Ageing, respectively [1, 34]. English Indices of Multiple Deprivation (IMD) were used by 10 studies to assess SES $[1,2,4,28-30,32-34,38], 7$ of which used the 2004 edition [1, 28-30, 32, 34, 38], 2 used the 2007 edition [2, 33] and one used the 2010 edition [4]. Scottish IMD (SIMD) were used by two studies, both of which used the 2006 edition [36, 37]. Two studies used the Carstairs Index $[27,39]$. One study used the Townsend index [31]. An unknown quintile-based deprivation index was used by one study [35]. A complete list of assessed domains is provided in Table 3.

\section{Risk of bias}

The risk of bias checklist for assessing the quality of the included studies is shown in Table 4, with the number of questions answered by each study for comparison. All studies recorded the age and gender of the study population. Of the 16 studies, only one included data from private hospital admissions [29]. Two reported the distance travelled by patients to receive hip replacement surgery $[1,32]$. Three studies had information on the rurality of patients' residences [1, 27, 32]. Four studies had information on patients' quality of life [4, 37-39] or their Body Mass Index (BMI) scores [4, 34, 37, 39]. Two studies met the most quality criteria, answering 12 out of 16 questions $(75 \%)[1,4]$. One study met the fewest quality criteria, answering only five questions (31\%) [31]. On average, the included studies answered nine questions for quality criteria (56\%). 


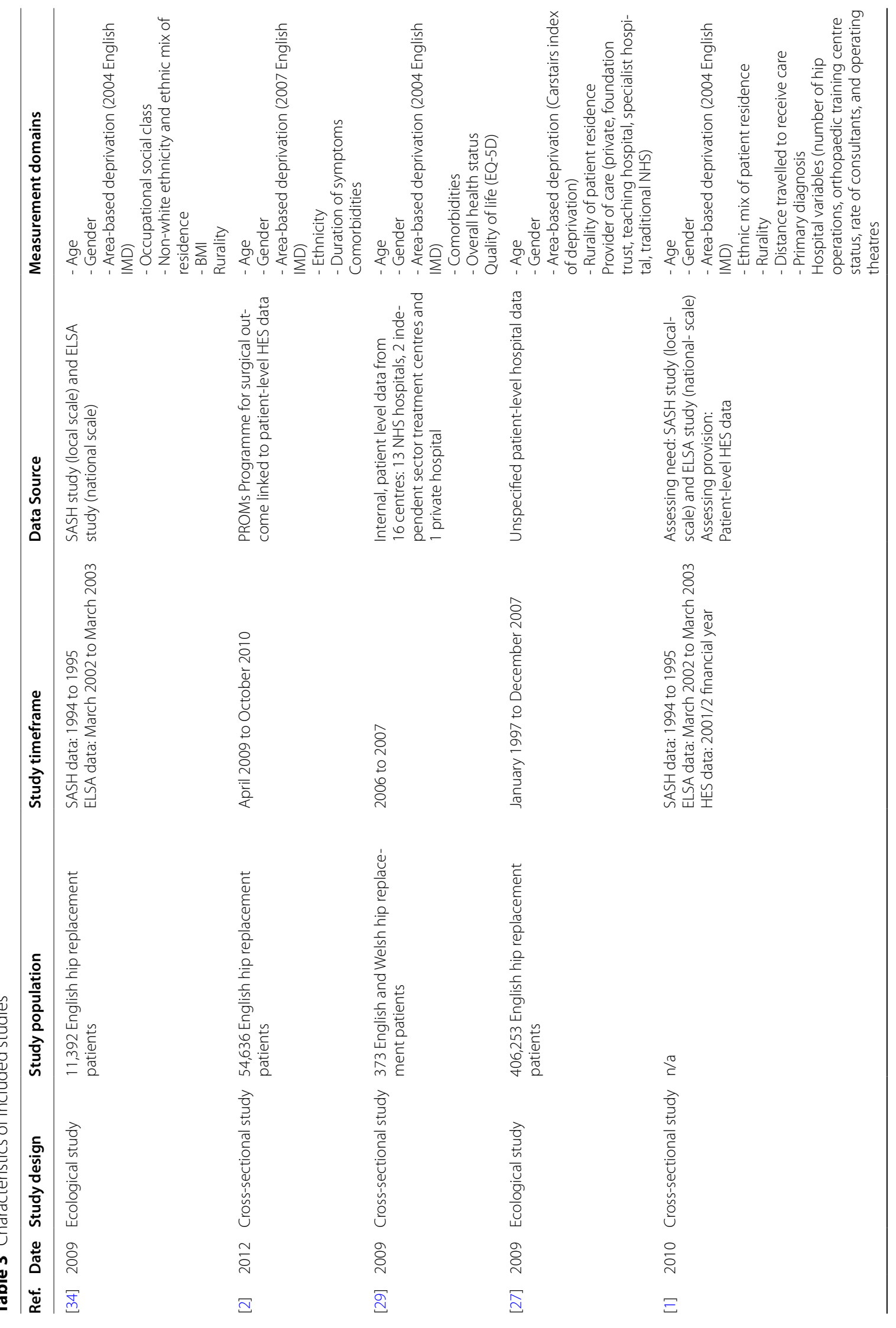




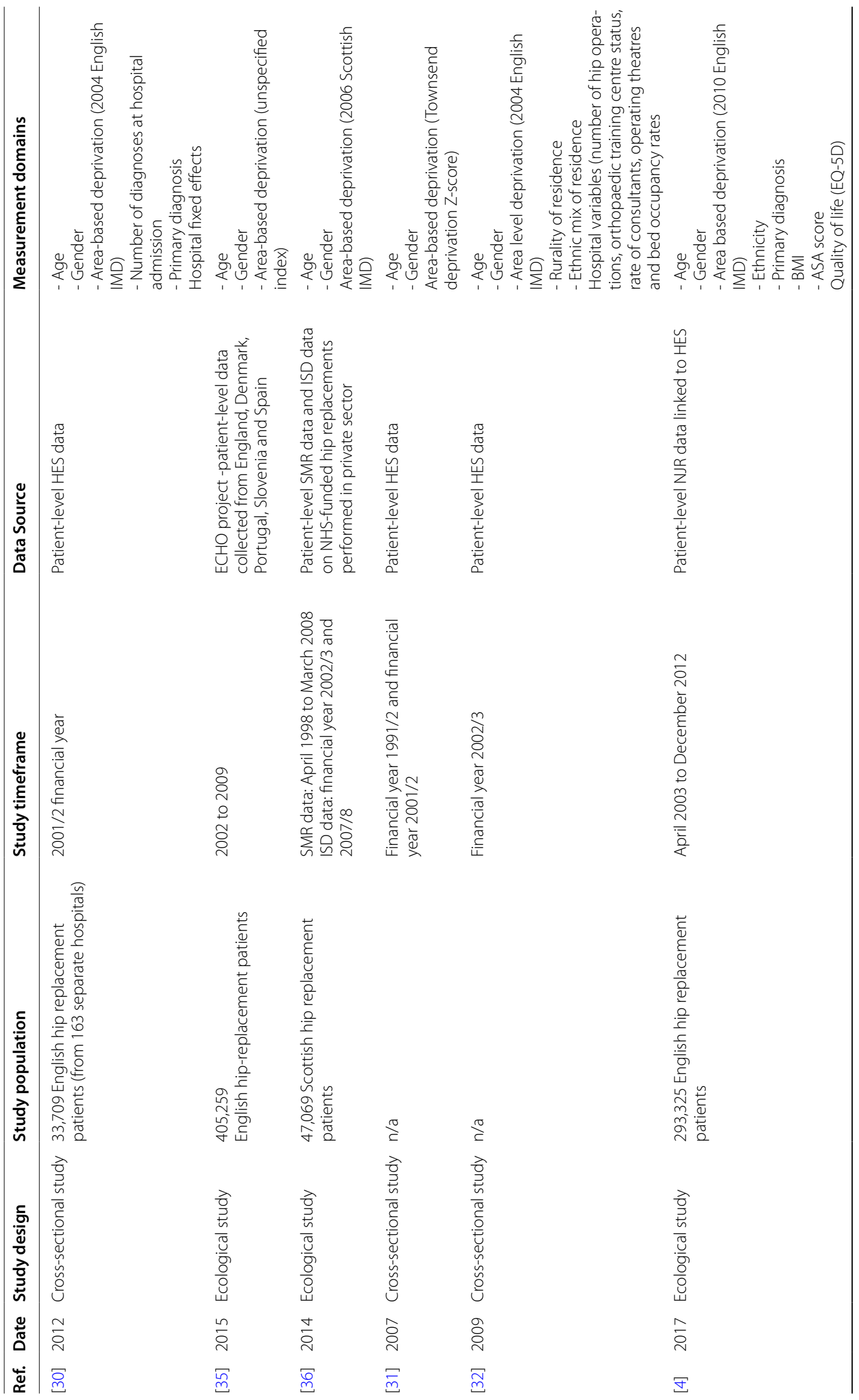




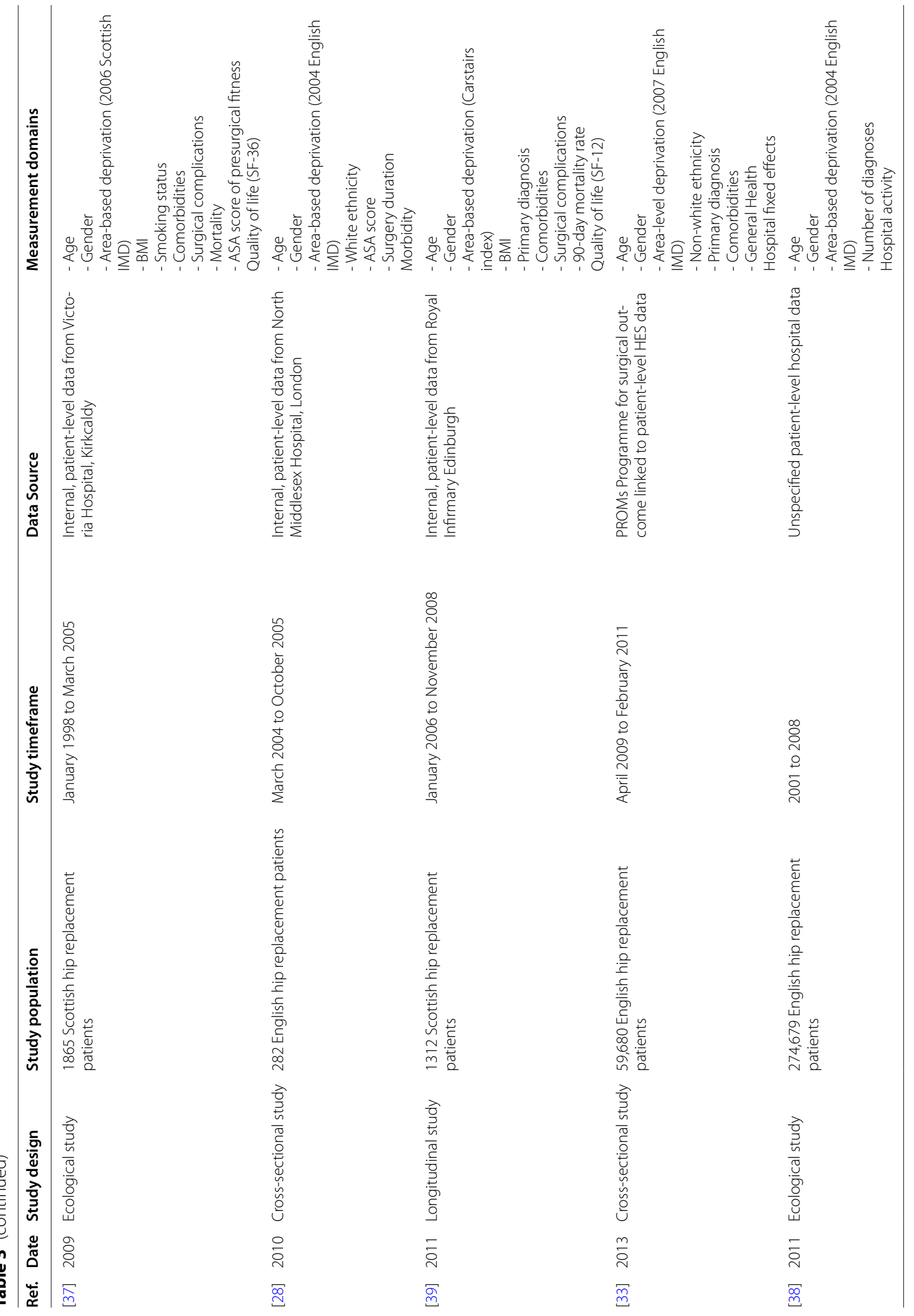




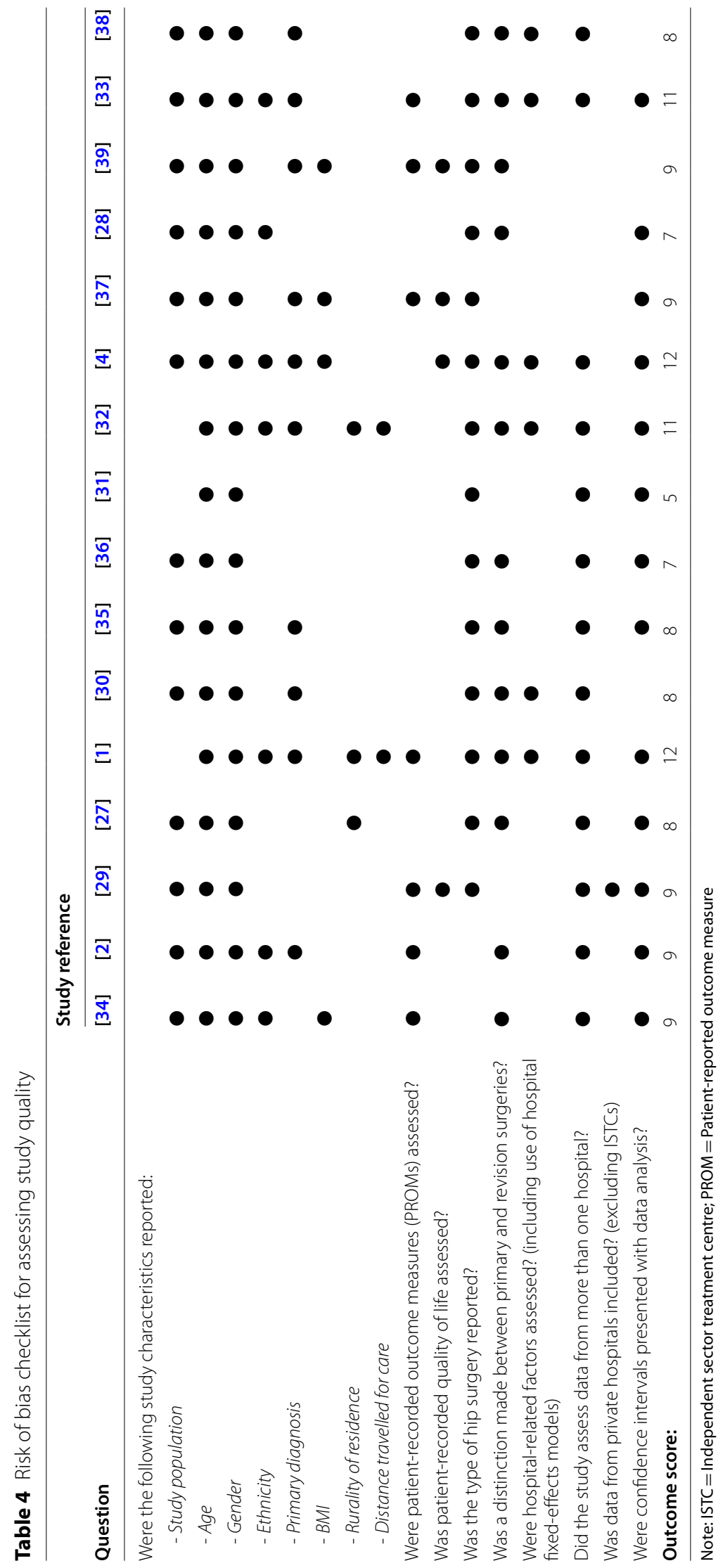




\section{Need for hip replacement surgery}

Table 5 shows the results for the three included studies that explored the need for hip replacement surgery [2, 29, 34]. Judge et al. [34] reported that 31.9 per 1000 English residents over 50 years old were in need of a hip replacement (CI: 28.4-35.8). Need was greatest for patients living in the most-deprived areas (IMD Q5). A stronger, linear relationship was found between occupational social class and need, with the lowest social class (class V: unskilled) having the greatest surgical need. Neuburger et al. [2] showed that, before surgery, mean Oxford Hip Score (OHS) was 3.6 points lower in the least-deprived patients than the most-deprived (IMD Q5 versus Q1) (CI: 3.4-3.9). Soljak et al. [29] reported a similar trend in OHS, with mean OHS 3.5 points lower in the leastdeprived patients than the most-deprived (IMD Q5 versus Q1) (CI: 0.078-0.274). However, adjusting for age, sex, general health, comorbidities and patientreported quality of life (EuroQol 5-dimension scale [EQ-5D]) lowered the level of significance, increasing the $p$-value from $p<0.001$ to $p=0.02$. Neuburger et al. [2] showed the most-deprived patients (Q5) experienced hip problems for a longer duration than the least-deprived (Q1) (CI: 1.03-1.20). Longer-term hip problems were also associated with patients younger than 50 years old compared to patients aged 71 to 80 (CI: 3.90-4.64). Despite this, Judge et al. [34] found that rates of need increased with age, with patients aged over 85 years experiencing the greatest need after adjustment for obesity. Patient BMI scores above 30 (obese) were a strong predictor for surgical need (CI: 1.9-2.8). Women have a greater reported need for surgery than men (CI: 0.6-0.9), with Neuburger et al. [2] reporting a mean presurgical OHS 2.3 points lower than for men. Despite this, women had a lower likelihood of reporting long-term hip problems than men (CI: 0.92-1.00). South Asian and Black patients had lower mean OHS than White patients. South Asian patients had mean OHS 2.7 points lower than White patients and Black patients had mean OHS scores 0.9 points lower. However, when comparing the mean OHS of Black and White patients, the adjusted differences were not statistically significant at the $5 \%$ level. Judge et al. [34] found that whilst univariable analyses suggested non-White patients had a greater surgical need, this effect was due to confounding from area-based deprivation and social class. Furthermore, no association was found between the ethnic mix of patients' residence and surgical need. Neither was any association found between the rurality of patient residence and surgical need.

\section{Access to hip replacement surgery}

Table 6 shows the results for the five included studies that explored overall access to surgery $[1,27,30,35,36]$. Judge et al. [1] reported $70 \%$ less provision relative to need in the lowest SES patients for England (95\% confidence interval: 0.30-0.33). Cookson et al. [35] showed that the ratio between provision and need increased by $12 \%$ (CI: $1.23-1.35$ ) from 2002 to 2009 . Judge et al. [1] reported that for every 1000 English people in need of hip replacement, only 44 will undergo the operation. Cookson et al. [35] report that, the average rate of hip replacement across England, in 2009, was 20.2 per 10,000 people over 35 years of age. When adjusted for age and sex, hip replacement rates were higher in the least-deprived quintile (Q1) than the most-deprived (Q5), with a Q5/Q1 ratio of 1.35 (CI: $1.25-1.45)$; that is, Q1 patients were $35 \%$ more likely to undergo surgery than Q5 patients. Kirkwood et al. [36] reported that while geographical inequality significantly improved in Scotland from 1998 to 2008 ( $p<0.001)$, socioeconomic inequality did not change significantly. Judge et al. [1] also noted greater access inequality in the West Midlands, London and the north of England, with patients in the south of England experiencing greater provision relative to need. Increased rurality in England was associated with greater provision relative to need, as were longer road travel times for care. Kirkwood et al. [36] reported that hip replacement rates were significantly lower in the most-deprived SIMD quintile (Q5) than any other quintiles (Q1-4).

In terms of waiting times, Laudicella et al. [30] showed that the most educated patients' (IMD Q1) waiting times for surgery were $16.5 \%$ shorter than for less educated patients (Q2-5). The same trend applied to patient income as patients with the lowest income (Q5) waited 7.5\% longer than patients with the highest income (Q1). From 1997 to 2000, Cooper et al. [27] reported that each decreasing quintile below Q1 (Carstairs index) was associated with an additional 1-2 week wait for surgery $(p<0.001)$. Despite this, by 2007 , they reported almost uniformly distributed waiting times across the deprivation quintiles. Cooper et al. [27] was the only accessrelated study to report an overall decrease in waiting time and SES inequality from 1997 to 2007. Judge et al. [1] reported that people aged 60-64 received more surgeries relative to need compared to those aged 50-59. Those aged over 85 also received less surgery (CI: 0.65-0.72). Laudicella et al. [30] also reported that patients aged 75 years and older waited $17-30 \%$ less than patients aged 45-54. These patients were also more likely to experience a greater number of disabilities. Cooper et al. [27] reported that men received $8 \%$ more surgeries relative to 


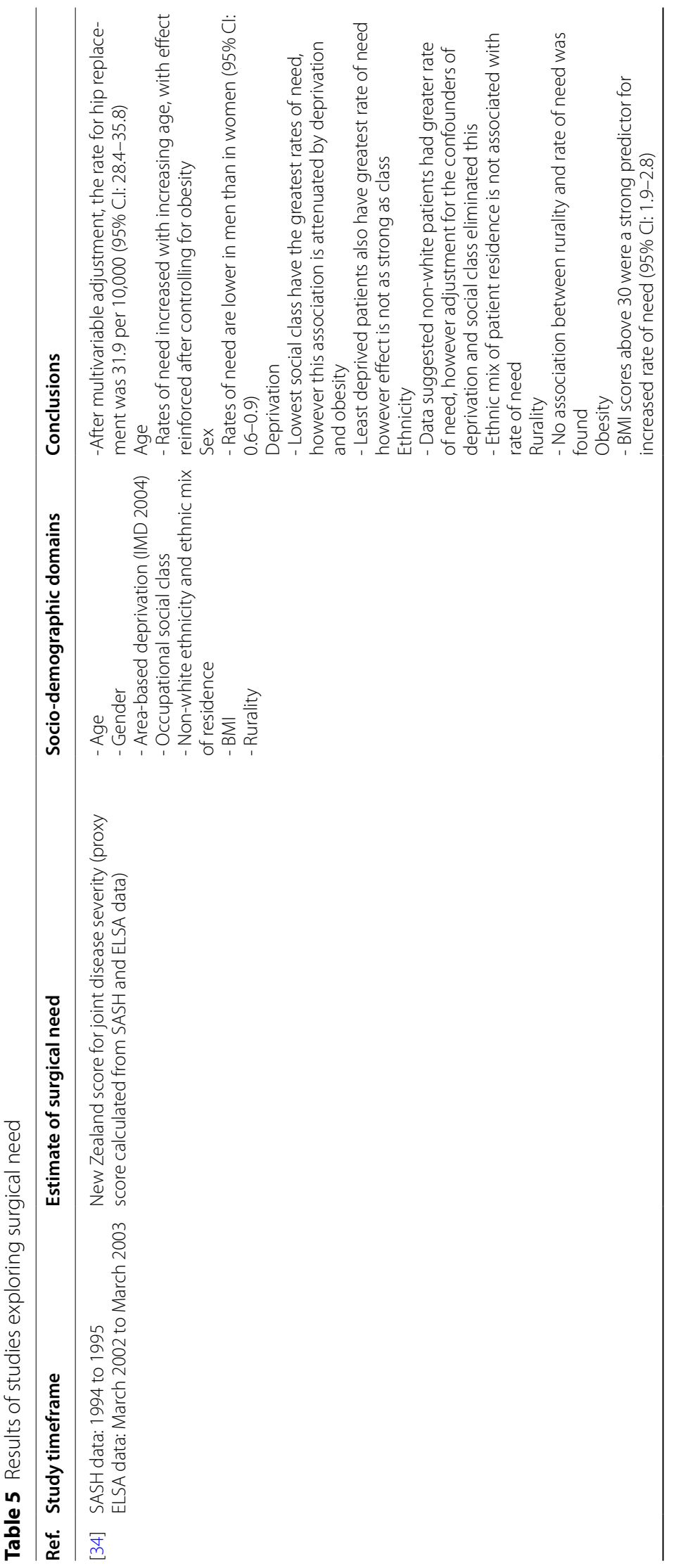




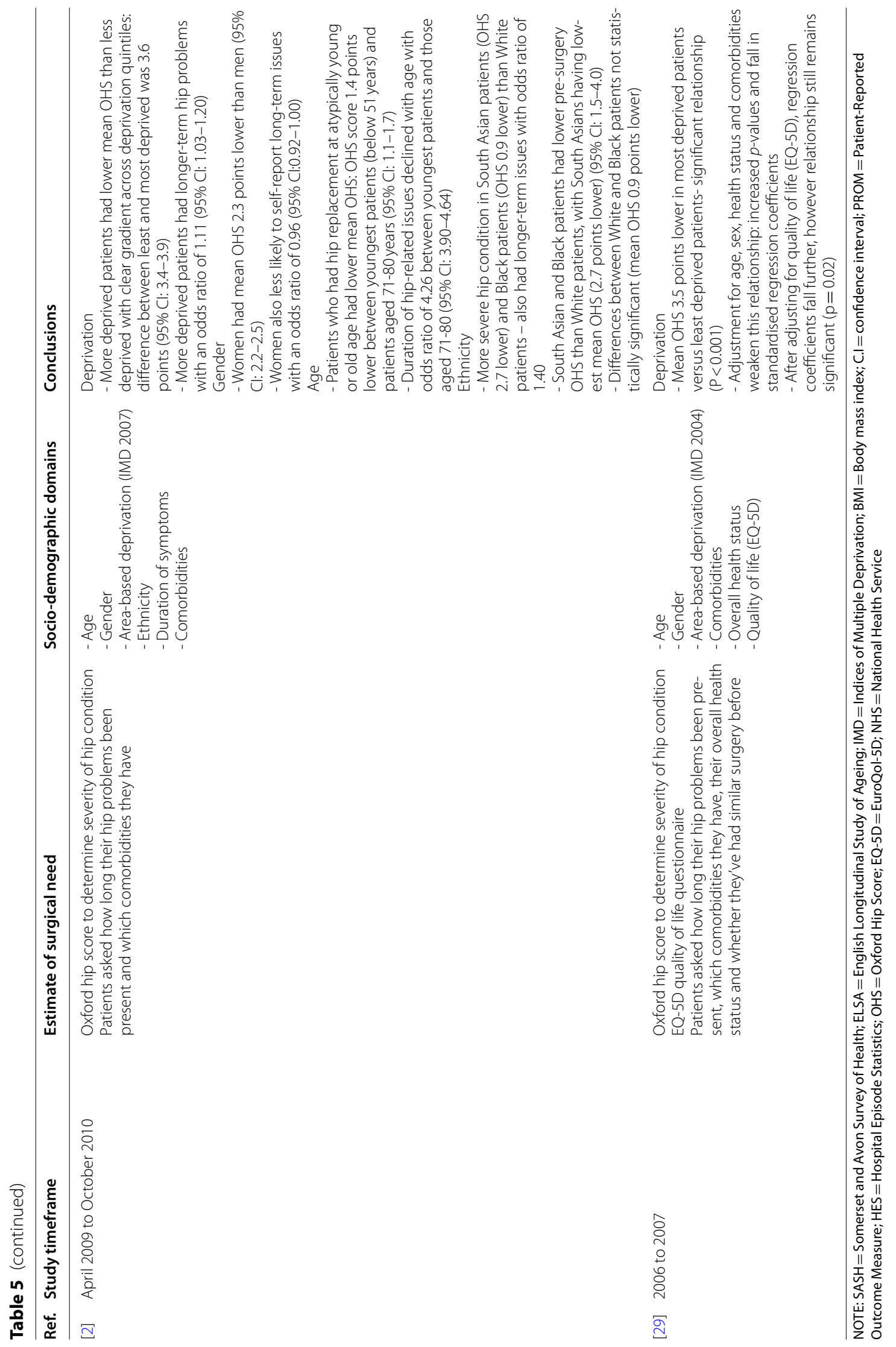




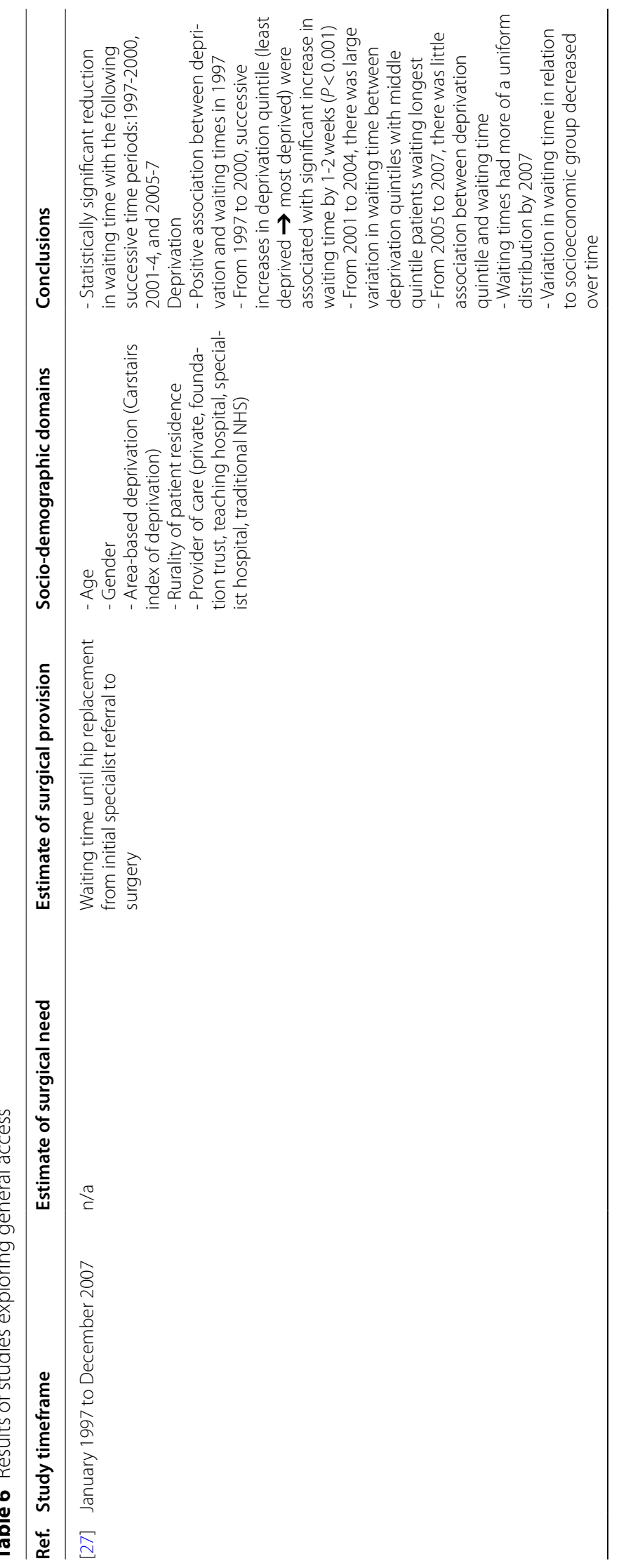




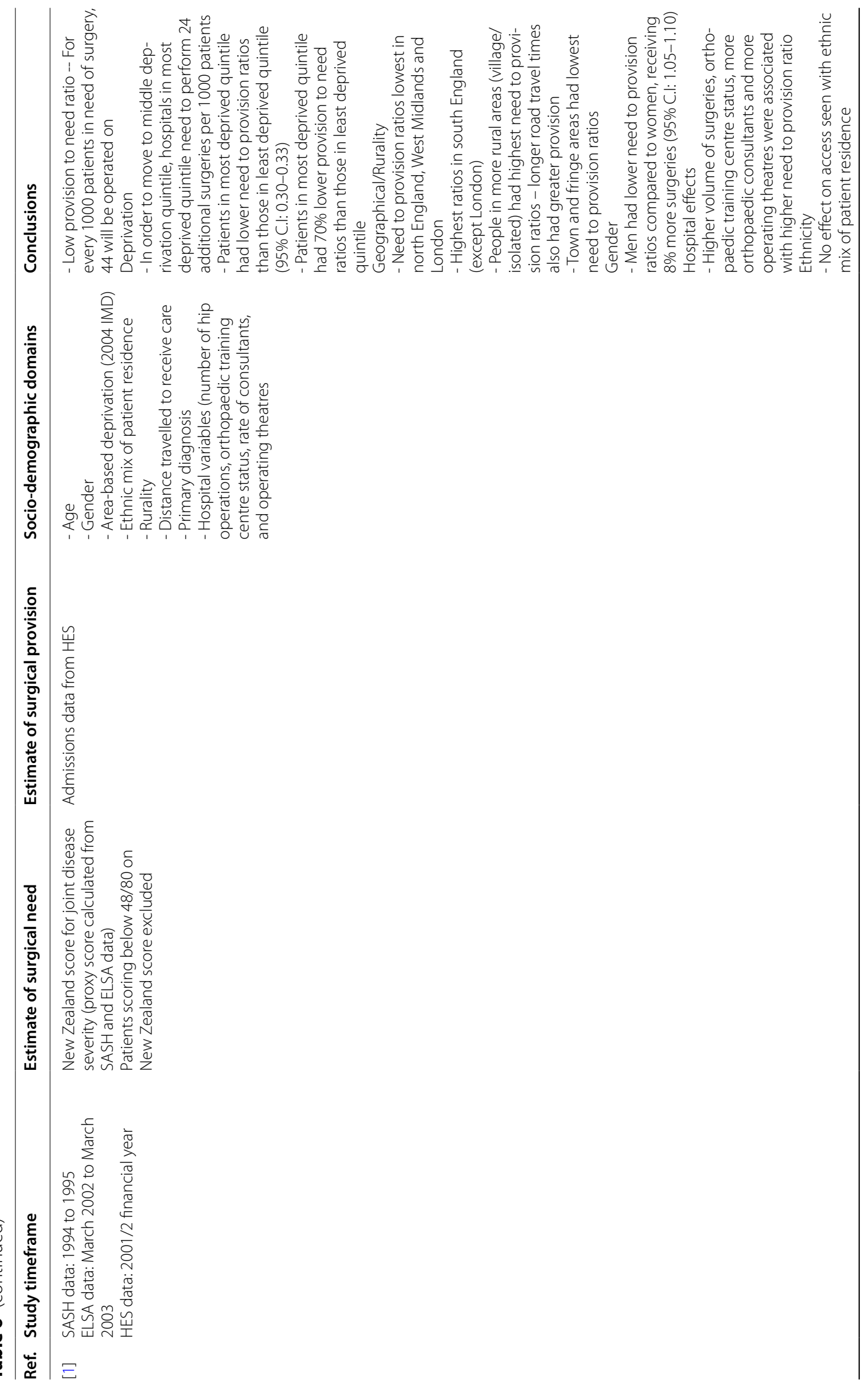




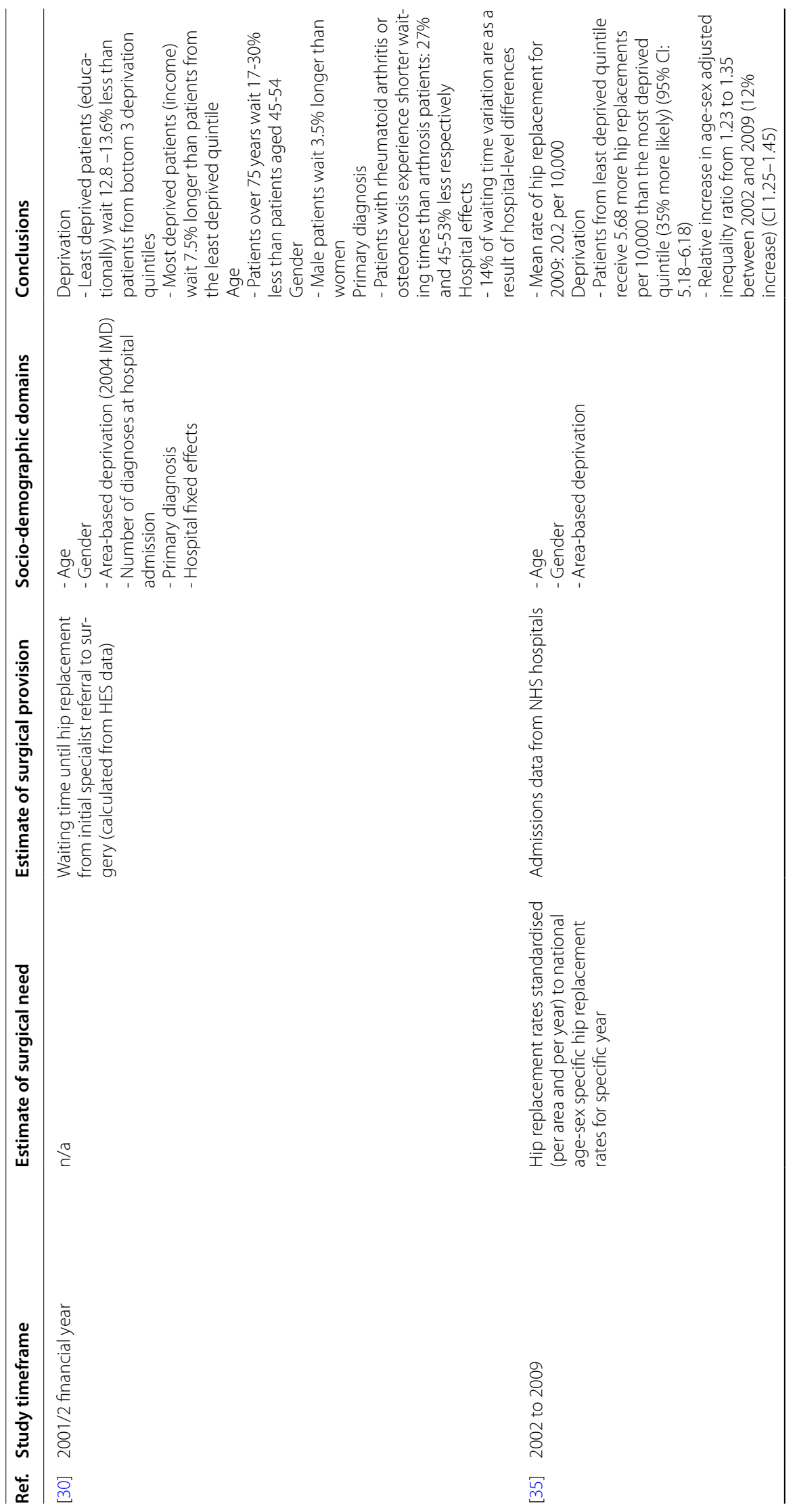




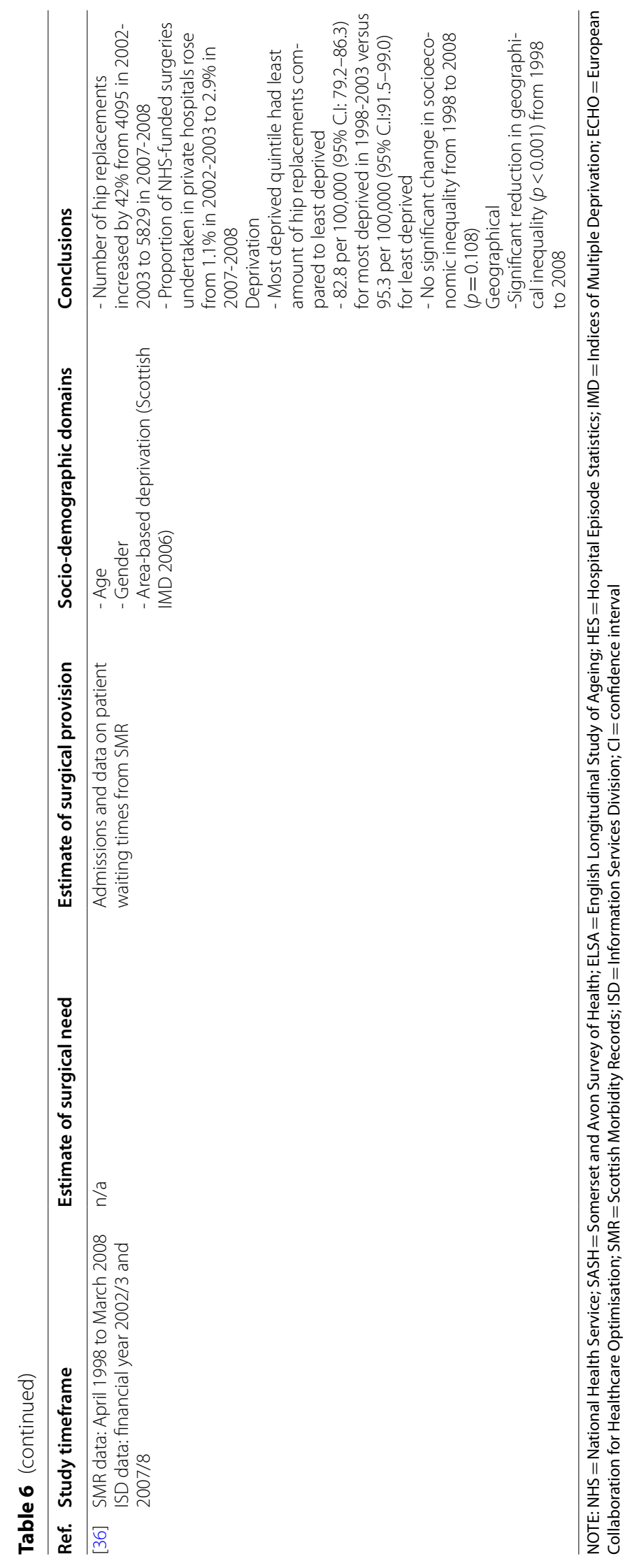


need compared to women (CI: 1.05-1.10). Despite this, Laudicella et al. [30] reported male patients as having to wait 3.5\% longer compared to female patients. Judge et al. [1] reported that the ethnic mix of patients' area of residence (represented as non-White people versus White people) did not affect access to hip replacement surgery.

\section{Provision of hip replacement surgery}

Table 7 shows the results for the three included studies that explored the provision of hip replacement surgery, as determined by the rate of surgery [4, 31, 32].. From 1991 to 2001, Cookson et al. [31] reported that the rate of hip replacement in England rose from 160 per 100,000 to 184 per 100,000 . An increase in provision was observed among more deprived patients, with utilisation rate ratios for the most-deprived quintile (Townsend index Q5) rising from 0.804 to 0.843 . The increase in surgical rate required for the rate of surgery in the most-deprived patients to match the rate in the least-deprived patients fell from 41 to $27 \%$. In patients aged 50 to 59 years, Judge et al. [32] found the most deprived had the greatest surgical provision. Despite this, an inverse effect was seen in patients over 85; provision decreased with increasing deprivation. Women received greater provision across all age groups than men; however, the effect was weakest in the oldest and youngest age groups. Geography influenced gender variation; men in the London Borough of Lambeth received $28 \%$ less provision than women, compared to men in Wansbeck, north-east England, who received 20\% more provision than women. However, Smith et al. [4] reported little difference in provision between men and women. Cookson et al. [31] reported that in both 1991 and 2001, surgical provision was lower than expected for patients in the lowest third of SES. Smith et al. [4] also reported fewer surgical procedures were performed on Black and Asian patients than expected. Ethnic minority patients were younger and had greater physiological ASA (American Society of Anaesthesiologists) fitness grade, but were likely to live in more deprived areas. Surgeries performed on Black patients were more likely to use uncemented hip prostheses instead of cemented prostheses. Despite this, Judge et al. [32] reported no differences in procedure related to patient ethnicity. Smith et al. [4] also reported that Black and Asian patients were more likely to receive hip replacements due to osteonecrosis, rheumatoid arthritis and congenital dysplasia compared to white patients. Surgical provision was greater in hospitals with more operating theatres and higher surgical rates. Despite this, hospitals with greater numbers of consultants, specifically anaesthetic consultants, had lower rates of provision. In terms of rurality, non-urban patients experienced greater surgical provision, as did patients living further from the hospital.
Surgical outcome of hip replacement surgery

Table 8 shows the results for the five included studies that explored surgical outcomes [28, 33, 37-39]. Preoperatively, Clement et al. [39] reported that the most-deprived patients (Carstairs deprivation category) [DEPCAT] (7 out of 7) scored 5.8 points lower than the least-deprived (DEPCAT 1) on a scale of self-reported hip condition (Oxford Hip Score [OHS]). Neuburger et al. [33] also reported a mean OHS 4.0 points lower in the mostdeprived patients (IMD Q5) versus the least-deprived (Q1). Jenkins et al. [37] reported that more deprived patients (SIMD Q5 versus Q1) had worse self-reported hip condition (Harris Hip Score (HHS)) pre-surgery (CI: $0.88-6.82$ ), at 6 months after surgery (CI: 1.92-8.14), and 18 months after surgery (CI: 0.74-8.35). At 6 months after surgery, Neuburger et al. [33] reported a mean OHS 5.0 points lower for the most-deprived patients (Q5) versus the least-deprived. The most-deprived patients were $3.2 \%$ more likely to report no improvement in their hip condition after surgery and were also more likely to report a decline in condition. Cookson and Laudicella [38] reported that the most-deprived patients remained in hospital after surgery $6 \%$ longer in 2001, falling to $2 \%$ longer by 2007 . At 18 months after surgery, Jenkins et al. [37] reported significantly worse mental and physical wellbeing in more deprived patients (Short-Form 36-point survey [SF-36] physical: $p<0.001$; SF-36 mental: $p<0.001)$. Neuburger et al. [33] identified that $33 \%$ of patients living in the most-deprived areas reported poor general health compared to $18 \%$ in the least-deprived areas. More deprived patients also had more comorbidities, except for cancer. Cookson and Laudicella [38] reported that patients with seven or more comorbidities stayed in hospital $58 \%$ longer than other patients in 2001 , increasing to $73 \%$ longer by 2007 . Clement et al. [39] reported that the comorbidity that predicted no improvement in condition 12 months after surgery was depression. In contrast, Jenkins et al. [37] reported no differences associated with SES and preoperative comorbidities. Despite this, a greater proportion of patients with an ASA status grade I (normal, healthy patient) were in the lowest deprivation quintile (Q5) compared to the highest quintile (Q1) (CI: 1.409-4.044). Another surgical risk identifier, the Physiological and Operative Severity Score for the enumeration of Mortality and Morbidity (POSSUM), was used by Hollowell et al. [28], who showed a modest socioeconomic gradient in POSSUM score, with surgical risk significantly decreasing from deprivation quintile Q5 to Q1 (IMD) $(p=0.04)$. However, no evidence was found between SES and postoperative morbidity. Clement et al. [39] also found no significant association between overall postoperative morbidity and SES but did find a significant association 


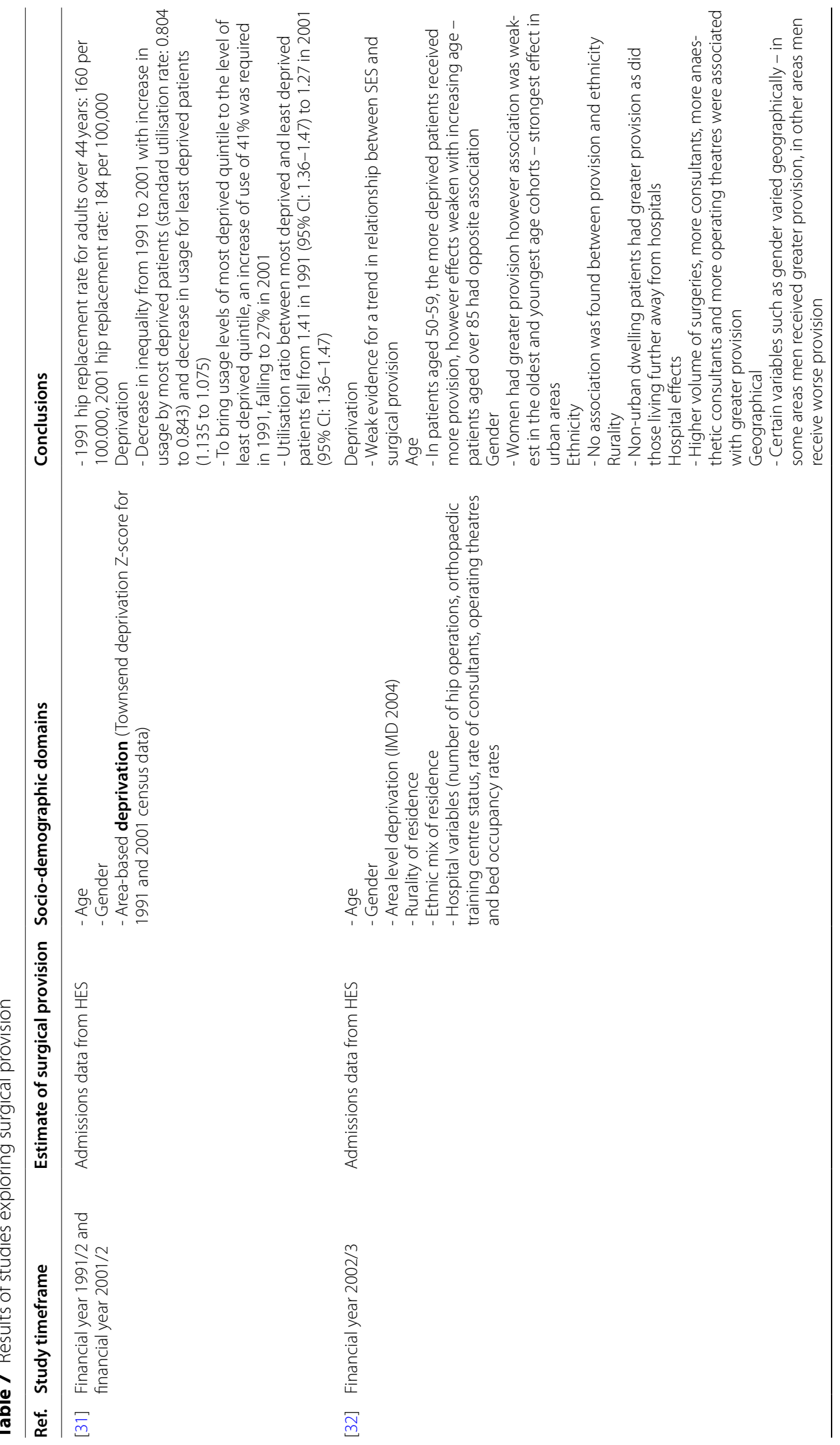




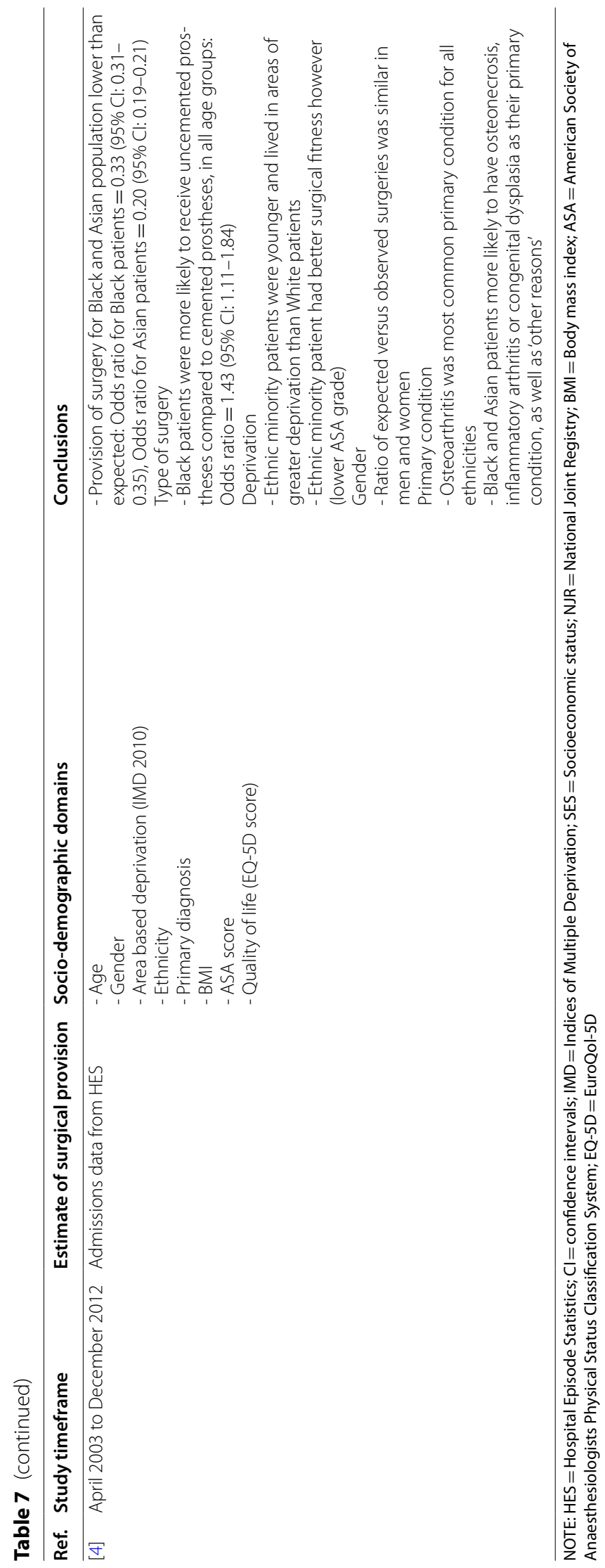




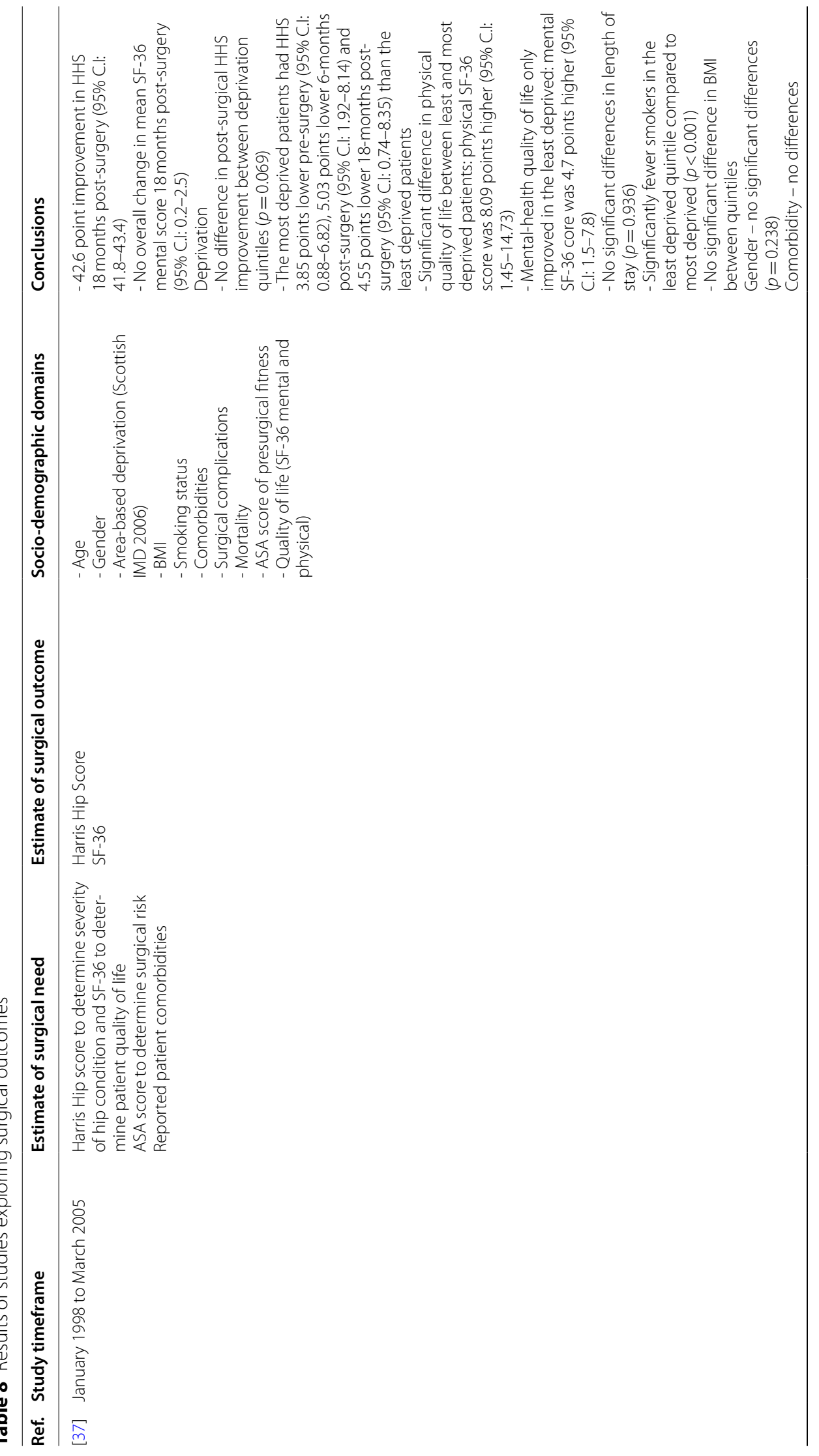




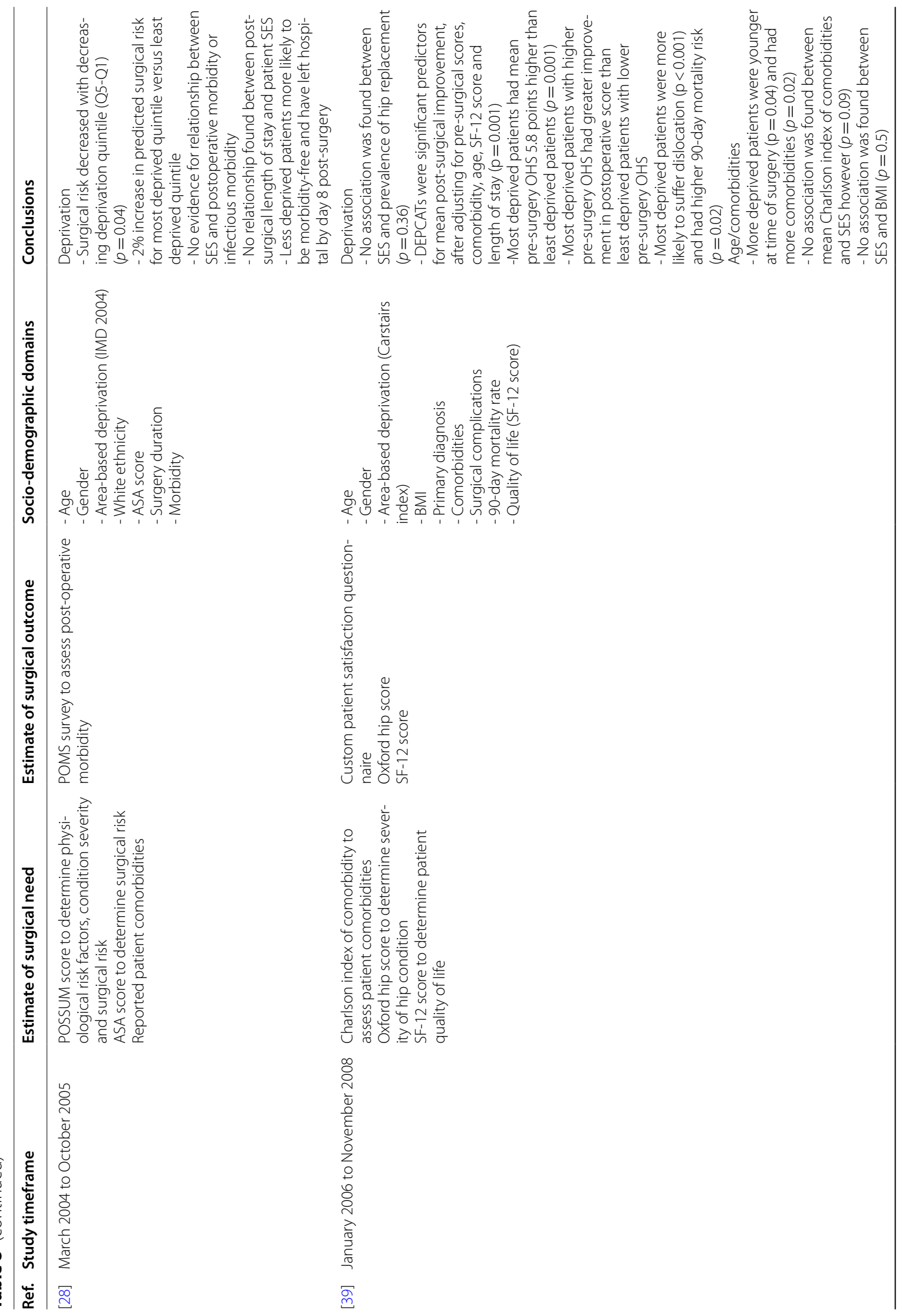




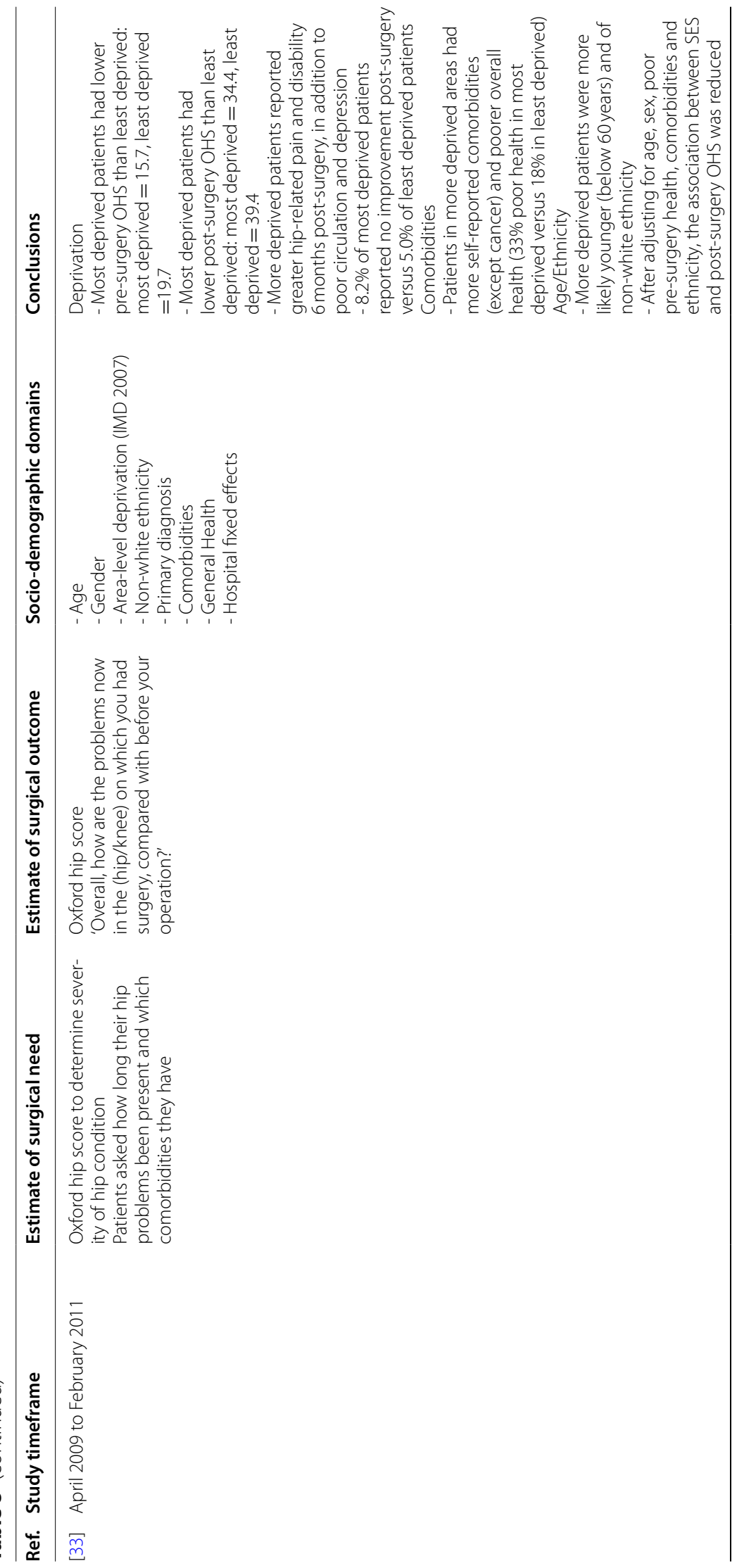




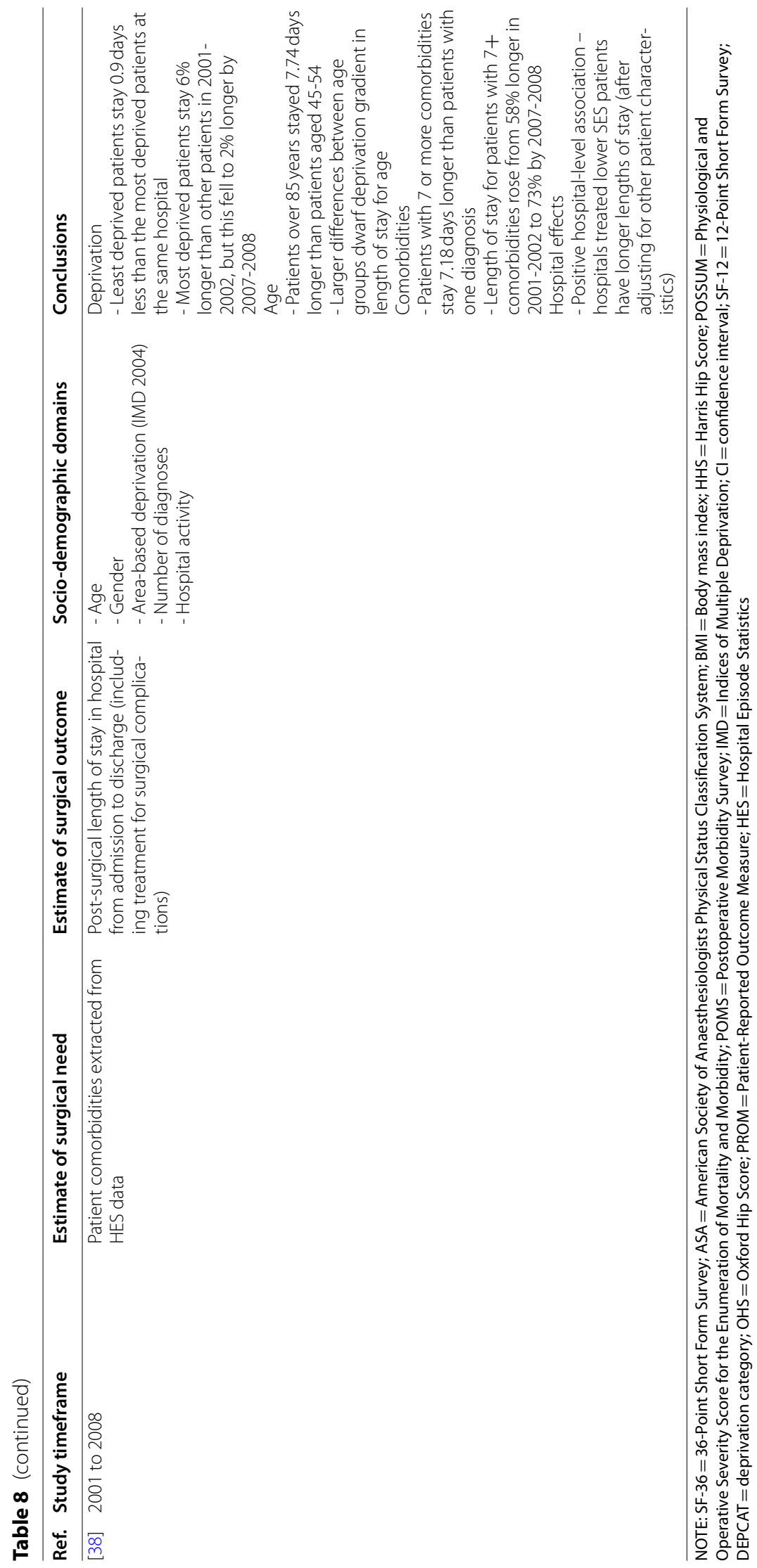


with post-operative hip dislocation in the most-deprived groups (DEPCAT 6 and 7) $(p<0.001)$. No significant difference between patients' SES and BMI was found by Clement et al. [39] ( $p=0.05$ for no association hypothesis) and Jenkins et al. [37] ( $p=0.68)$. Jenkins et al. [37] showed a significantly lower proportion of active smokers in the least-deprived quintile $(\mathrm{Q} 1)$ compared to the most-deprived (Q5).

\section{Discussion}

\section{Socioeconomic inequalities in hip replacement surgery}

Socioeconomic inequality was the most widely measured variable affecting access. In England, the mostdeprived patients received $70 \%$ lower surgical provision relative to need compared to the least-deprived [1]. One study reported that some lower SES patients reported worse hip condition after surgery [33]. In contrast, a Dutch study [40] found no evidence of educational levels impacting postoperative patient quality of life, as assessed by the SF-36 questionnaire. A Swedish study [41] also investigated education-related deprivation but found no association with postoperative mortality risk, questioning its applicability as a sole indicator of deprivation. Interestingly, a study [42] focusing only on older-age patients (46 to 64 years old) found the only commonly used socioeconomic indicator independently associated with health was income. Education, social class and occupational complexity had no independent effects on health in older-age patients. This is an important consideration for future studies investigating hip replacement surgery as osteoarthritis typically starts at around 50 years of age [43]. However, one study found a stronger relationship between social class and surgical need than English IMD and surgical need [34]. Some study cohorts were not representative of the wider UK population due to fewer patients in more deprived IMD quintiles [2,33]. This is a notable sampling bias that can reduce the reliability of deprivation indicators such as the IMD. None of the included studies provided evidence that authors implemented controls for measuring deprivation in older age groups. The Income Deprivation Affecting Older People (IDAOPI) is a supplementary index in the English IMD, [44] tailored to assess income deprivation for over-60-year-olds. A study that specifically focused on the income index of IMD, one of seven areas assessed in the IMD to show overall deprivation, did not use the IDAOPI [30], increasing the risk of sampling bias. Both the Carstairs and Townsend deprivation indices use employment as part of their assessment of deprivation [44]. Over the timeframes (1991 to 2008) of the studies that used these indices [27, 31, 39], the UK employment rate of over 65-year-olds was only around 5.5 to $7.3 \%$ [45]. With a lower employment rate in more elderly patients, employment is an inadequate indicator of deprivation for hip replacement patients. Furthermore, hip osteoarthritis has been associated with early retirement [46], which suggests the actual employment rate for hip replacement patients is lower than the UK average. Future studies must cautiously consider which measure of socioeconomic deprivation to choose, ensuring that the outcome will be valid for their study's sociodemographic characteristics.

\section{Ethnicity-related inequalities in hip replacement surgery}

Three studies exploring ethnic mix found no association between access, need or provision of surgery and ethnic mix of patient residence [1, 32, 34]. This contrasts with evidence from the USA, where a study in individuals with federal health insurance showed that Black patients were $30 \%$ less likely to undergo hip replacement surgery than White patients, after age and gender-standardisation [47]. Furthermore, Black patients were also shown to have worse preoperative and postoperative pain and function scores [48]. One of the studies reporting no association between ethnic mix and surgical need also reported that while initial data reported an association, this was eliminated by controlling for social class and deprivation [34]. Through an awareness of the intersectionality between ethnicity and SES, studies can explore distinct trends in inequality without conflating the two variables. Ethnicity-related inequalities have been shown to be distinct from SES in a study assessing income-based inequality [47]. In this case, income-based inequality was a more suitable indicator for assessing SES as it allows for individual-level analysis. Ethnic mix and IMD are area-level ecological measures that are not able to show causation or be extrapolated to the individual level. It is essential to recognise this ecological bias, as in order for ethnic inequality to be distinctly explored, both ethnicity and socioeconomic status need to be individually assessed.

Two studies explored distinct ethnic minority groups $[2,4]$. One study found Black and Asian patients are more likely to suffer from rheumatoid arthritis and osteonecrosis as their primary condition before hip replacement [4]. Both conditions were also associated with shorter waiting times due to their increased severity over osteoarthritis [30]. When only osteoarthritis patients were assessed, more severe hip condition was shown in Black and South Asian patients [2] - however the minimal clinically important differences (MCID) in OHS were not met [49]. Nevertheless, the increased urgency of surgery in patients with osteonecrosis and rheumatoid arthritis [30] presents a potential confounding variable. Also, the majority of studies that 
controlled for primary diagnosis only removed cancer or trauma-related hip replacements [1,31, 34,39], which are known to disproportionately affect lower social classes [35]. To reduce the impact of primary diagnosis as a confounder, future studies might focus on specific preoperative diagnoses. However, it must be noted that there is strong evidence that the quality of ethnicity data reported by individual hospitals varies [50]. Studies investigating differences between individual ethnic minorities should consider this potential for misclassification error in their sensitivity analyses. Furthermore, cross-sectional studies exploring trends over multiple hospitals should ensure other inter- and intra-hospital variables are not responsible for observed patient-level trends [30, 33, 38]. In standard regression analysis, hypothesised unequal surgical provision in ethnic minorities could be explored using rate of surgery as a dependent variable and the ethnic diversity of hospital staff as a key predictor. Even if this investigation were able to prove the original hypothesis, unobserved variables such as differences in primary diagnosis introduce omitted variable bias [51]. Hospital fixed-effects models include hospital dummies in the regression analysis to control for observed and unobserved variables, such as primary diagnosis, diminishing potential omitted variable bias [52]. Studies performing regression analyses should consider using a hospital fixed-effects model to mitigate the impact of omitted variable bias.

\section{Geographical inequalities in hip replacement surgery}

Scottish geographical inequality in access to hip replacement surgery declined from 1998 to 2008 [36], however, England has a distinct north-south divide in surgical access [1]. The higher the need-to-provision ratio, the greater the gap between high surgical need and low surgical provision, with ratios being the highest in southern England (except Greater London) and lowest in northern England. Variations exist within this divide, with domains such as male gender having pockets of higher provision in low need-to-provision ratio areas [32]. This is despite evidence showing men had lower surgical need and provision compared to women $[1,32,34]$. Studies have suggested a 'postcode lottery' effect might be responsible [36]. This effect describes certain areas that provide greater provision due to discrepancies in resource allocation by local CCGs. No relationship between rurality and need was found by one study [34]; however, need-to-provision ratios were higher in rural areas [1]. This contrasts with findings that urban hospitals with greater surgical capacity have greater surgical provision [1, 32]. However, higher provision ratios for rural patients provide a potential explanation for studies that found associations between longer travel times for treatment and increased provision [1, 32]. Differences in rurality also affect arealevel deprivation measures, such as the IMD. A US study showed that area-level deprivation measures significantly disagreed with individual-level deprivation measures in rural-urban mix areas [53]. A new poverty index is currently under development by the Department of Work and Pensions as an individual-level alternative to deprivation indices [54]. It is hoped future studies may utilise this index to provide more reliable data on healthcare inequalities across the UK. One method the UK government has used to attempt to reduce geographic inequality was creating independent sector treatment centres in 2002 [55]. These are private hospitals contracted by the NHS to conduct elective procedures. One included study [36] reported a reduction in NHS-funded private hip replacements in Scotland from 2008 to 2011 from 8.3 to $0.8 \%$. However, in England, private hospitals conducted $30 \%$ of all NHSfunded hip replacements in 2017-18 [56]. Increases in NHS-funded private surgeries have been associated with the diversion of funds from the NHS to the private sector [57]. In Scotland this has resulted in significantly reduced direct NHS surgical provision $(P<0.01)$, and a wider socioeconomic gap in provision, measured using SIMD. While provision inequity between socioeconomic groups is still apparent in the UK, evidence shows the gap has fallen over time in England [27, 31, 38]. Consequently, an increase in NHS-funded private surgeries threatens to weaken past improvements in socioeconomic and geographical inequality. With fears regarding the privatisation of the NHS increasing [58], researchers should investigate the relationship between the proportion of NHS-funded surgeries and socioeconomic inequality in the UK.

\section{Lifestyle and comorbidity inequalities in hip replacement surgery}

Increasing numbers of CCGs in the UK have begun implementing rationing measures for smokers and obese patients [59]. Concerns have been raised over such measures, with arguments that obesity and smoking are linked to lower SES and therefore, rationing would disproportionately affect lower SES patients. Significantly fewer current smokers were observed in more deprived quintiles $(p<0.001)$ [37]. Despite this, two studies [37, 39] investigating surgical outcomes showed obesity as having no relationship to SES. In addition, evidence suggests that other preoperative comorbidities, which are more common in lower SES patients [2], are not perceived as an access barrier to hip replacement surgery [60]. Nevertheless, it is vital 
that regardless of the involvement of SES, patients with higher BMI scores do not face discrimination. Recent evidence [61] from the US shows that while obesity is linked to a greater risk of surgical complication, 6-month postoperative SF-36 physical wellbeing scores were similar between obese and non-obese hip replacement patients. Furthermore, a study [62] investigating smokers, ex-smokers and non-smokers found no clinically important difference in postoperative patient-reported outcome measures (PROMs) between groups, although greater mortality and complication risk were observed. This evidence shows that the basis behind smoking and obesity-related rationing measures is weaker than suggested, and such measures should be reviewed to ensure they do not unnecessarily discriminate. As of 2009, the NHS has required preoperative and postoperative PROMs to be collected for all hip replacement surgery patients [63]; however, completing these questionnaires is not mandatory. Younger, deprived, non-white men who live alone and have poorer quality of life have been linked to higher non-response rates. Caution should be exercised when interpreting outcomes based solely on PROMs, as non-response bias may cause misrepresentation of the groups that face the greatest healthcare inequality. Another issue faced when assessing PROMs is what change in score can be considered clinically meaningful. For the OHS, the MCID was calculated to be a 5-point increase or decrease [49]. Of the four [2, 29, $33,39]$ included studies that used the OHS, two [33, 39] achieved the MCID necessary to prove their association between deprivation and surgical outcome. The other two studies [2,29] failed to reach the MCID, harming the validity of reported access inequalities in age, gender, ethnicity and deprivation despite their statistical significance. Despite this, one study [29] still reported their findings as statistically highly significant, as the reported $p$-value was $<0.001$. One included study [37] used the HHS; however, scores failed to achieve the MCID of between a 7- and 10-point [64] change. No MCID values could be found for the New Zealand score used by two included studies. Researchers must ensure that the clinical importance of findings is not purely based on statistical significance, and relevant MCIDs are used for the intervention being assessed and PROM used.

\section{Limitations of review}

Only one study had Welsh data and no studies had Northern Irish data. Excluding large samples of the UK population introduces selection bias, as the missing population data may have changed the pattern of inequalities described. Consequently, a narrower approach individually focussing on England or Scotland may have been more suitable. While a lack of research may be responsible for the lack of Welsh and Northern Irish data, it is also possible that geographical search criteria may have been imprecise. A custom UK geographical filter was used for the MEDLINE database search [65]; it was only effective for that specific database (Ovid). The simplified filter used for other databases may have excluded relevant studies. Development of an automated, internet or softwarebased tool to remap search syntax between different databases would allow the custom filter to work in other databases. The risk of bias is challenging to assess for observational studies and is further limited by the included studies' data heterogeneity. Different checklist questions may have different weightings on study bias, making interpretation of summary scores challenging. There is a need for a standardised methodology to assess the risk of bias in observational studies. This methodology must be easy to apply and allow identification of individual risks of bias, whilst facilitating quick comparison between the overall risks of bias in different studies.

\section{Conclusion}

This review summarises the available literature on access inequalities in hip replacement surgery for the UK. While the heterogeneity of study outcomes and methodology made drawing conclusive evidence challenging, it is clear that access inequality is a major issue in the UK. Potential inequalities in pre-surgical patient consultation were not explored in the included studies. Patient diagnosis and referral to surgery may be impacted by implicit biases present in practitioners, such as an ethnic bias in pain evaluation for Black patients [66]. Despite the unknown prevalence of such ethnic biases, their potential impact signals the importance of increasing workforce diversity, in addition to mandatory implicit bias training for NHS staff. This review demonstrates that there is a shortage of studies that assist in understanding the relationship between sociodemographic or socioeconomic variables and health inequalities. There is a need for bigger studies with more variables based on routinely gathered healthcare data. These studies need to be complemented by PROMs and ethnographic approaches to gather patient narratives. This will assist the development of better services to address inequalities. Given ongoing protests for racial equality and the impact of the COVID-19 pandemic, now is a crucial time to tackle gaps in equality and prevent their growth. 


\section{Appendix 1}

Table 9 Full database search strategy for included studies

\begin{tabular}{|c|c|c|c|}
\hline \multirow[b]{2}{*}{ PICo tool ${ }^{\dagger}$} & \multicolumn{3}{|l|}{ Search terms } \\
\hline & MEDLINE (Ovid) & PubMed & Web of Science \\
\hline Population & $\begin{array}{l}\text { exp Arthroplasty, Replacement, Hip/ } \\
\text { OR exp. Hip Joint/ } \\
\text { OR exp. Hip Prosthesis } \\
\text { OR exp. Osteoarthritis, Hip/ }\end{array}$ & $\begin{array}{l}\text { ((Arthroplasty, Replacement, Hip [mh]) OR } \\
\text { (Hip Joint [mh]) } \\
\text { OR (Hip Prosthesis [mh]) OR (Osteoarthritis, } \\
\text { Hip [mh])) }\end{array}$ & $\begin{array}{l}\text { TS = hip arthroplasty } \\
\text { ORTS=Hip Joint ORTS=Hip Prosthesis } \\
\text { ORTS=Hip Osteoarthritis }\end{array}$ \\
\hline Interest & $\begin{array}{l}\text { exp Socioeconomic Factors/ } \\
\text { OR exp. Social Class/ } \\
\text { OR exp. Ethnic Groups/ OR exp. Minority } \\
\text { Groups OR Demography.mp }\end{array}$ & $\begin{array}{l}\text { ((Socioeconomic Factors [mh]) } \\
\text { OR (Social Class [mh]) OR (Ethnic Groups } \\
\text { [mh]) OR (Demography [TIAB]) OR (Minority } \\
\text { Groups [mh])) }\end{array}$ & $\begin{array}{l}\text { TS = Socioeconomic Factors OR TS=Social } \\
\text { Class ORTS = Ethnic Groups ORTS = Minority } \\
\text { Groups ORTS=Demography }\end{array}$ \\
\hline Context I & $\begin{array}{l}\text { exp Health Services Accessibility/ } \\
\text { OR exp."Health Services Needs and } \\
\text { Demand"/ OR exp. Social Justice/ OR exp. } \\
\text { Health Care Reform/ } \\
\text { OR exp. Delivery of Health Care/ } \\
\text { OR exp. Health Planning/ } \\
\text { OR exp. Health Policy/ OR exp. Healthcare } \\
\text { Disparities } \\
\text { OR exp. Health Status Disparities } \\
\text { OR Health Services.mp OR (equalit\$ OR } \\
\text { inequalit\$ or equit\$ or inequit\$).tw }\end{array}$ & $\begin{array}{l}\text { ((Health Services Accessibility [mh] } \\
\text { OR (Health Services Needs and Demand } \\
\text { [mh]) } \\
\text { OR (Social Justice [mh]) OR (Health Care } \\
\text { Reform [mh]) } \\
\text { OR (Delivery of Health Care [mh]) } \\
\text { OR (Health Planning [mh]) } \\
\text { OR (Health Policy [mh]) OR (Healthcare } \\
\text { Disparities [mh]) } \\
\text { OR (Health Status Disparities [mh]) } \\
\text { OR (Health Services [TIAB]) } \\
\text { OR (equalit*) } \\
\text { OR (inequalit*) } \\
\text { OR (equit*) } \\
\text { OR (inequit*)) }\end{array}$ & $\begin{array}{l}\text { TS = Health Services Accessibility OR } \\
\text { TS = Health Services Needs } \\
\text { ORTS= Health Services Demands OR } \\
\text { TS = Social Justice OR TS=Health Care Reform } \\
\text { ORTS=Delivery of Health Care } \\
\text { ORTS=Health Planning } \\
\text { ORTS=Health Policy } \\
\text { ORTS=Healthcare Disparities } \\
\text { ORTS=Health Status Disparities } \\
\text { ORTS=Health Services ORTS = equalit* OR } \\
\text { TS = inequalit* } \\
\text { ORTS = equit* } \\
\text { ORTS = inequit* }\end{array}$ \\
\hline Context II & $\begin{array}{l}\text { Custom geographical filter developed by } \\
\text { Ayiku et al. [65] }\end{array}$ & $\begin{array}{l}\text { (United Kingdom OR England or Wales OR } \\
\text { Scotland OR Great Britain OR GB OR UK) }\end{array}$ & $\begin{array}{l}\text { (ALL }=(\text { United Kingdom OR England or Wales } \\
\text { OR Scotland OR Great Britain OR GB OR UK)) }\end{array}$ \\
\hline
\end{tabular}

${ }^{\dagger}$ To complete the search, PICO tools were combined as follows: Population AND Interest AND Context I AND Context II

- 'exp' refers to an exploded search whereby more niche MeSH keywords relating to the wider concept were captured

-.'mp' refers to a multi-purpose search whereby the specific term is searched for in several fields of the article, including the title and abstract

- '.tw' refers to a text word search whereby the specific term is searched for only in the title and abstract for added specificity

- '[mh]' refers to a MeSH specific search which ensures the terms are searched as MeSH-specific keywords only

- '[TIAB]' refers to title and abstract search whereby the specific term is searched for only in the title and abstract

-'TS=' refers to a topic search whereby the specific term is searched for in several fields of the article, including the title and abstract

' $\$$ ' and ${ }^{\prime * \prime}$ are truncation symbols allowing for a variety of word-endings to be captured. 


\section{Appendix 2}

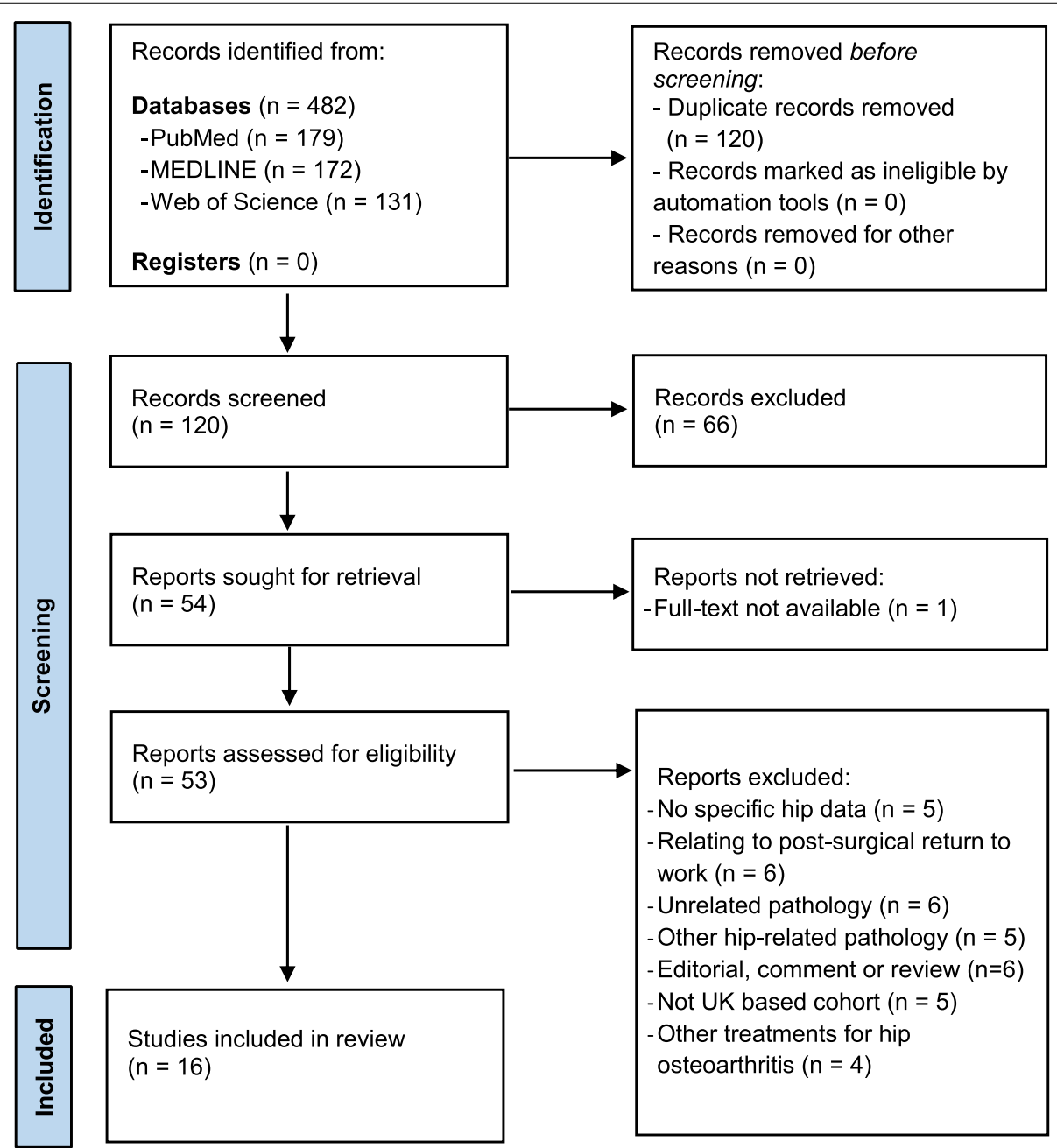

Fig. 1 PRISMA flow diagram [adapted from Page et al. [23]]

\section{Abbreviations}

ASA: American Society of Anaesthesiologists Physical Status Classification System; BMI: Body mass index; CCG: Clinical Commissioning Group; DEPCAT: Deprivation category; EQ-5D: EuroQol-5D quality of life score; HHS: Harris Hip Score; HES: Health Episode Statistics; IDAOPI: Income Deprivation Affecting Older People Index; IMD: Indices of Multiple Deprivation; MeSH: Medical Subject Headings; MCID: Minimal Clinically Important Difference; NHS: National Health Service; OECD: Organisation for Economic Co-operation and Development; OHS: Oxford Hip Score; PROM: Patient-reported outcome measure; POSSUM: Physiological and Operative Severity Score for the Enumeration of Mortality and Morbidity; PICO: Population, Intervention, Control, Outcome model; PICo: Population, Phenomena of Interest, Context model; PRISMA: Preferred Reporting Items for Systematic Review and Meta-Analyses; SIMD: Scottish Indices of Multiple Deprivation; SES: Socioeconomic status; SF-36: 36-Item Short Form Survey.

\section{Acknowledgements}

The authors would like to acknowledge the support from the Medical school of the University of Exeter for doing this project. In addition, we would like to thank the anonymous reviewers for their insightful comments.

\section{Authors' contributions}

The authors have equal contributions in preparing this manuscript. All authors read and approved the final manuscript.

\section{Funding}

This research did not receive any specific grant from funding agencies in the public, commercial, or not-for-profit sectors.

\section{Availability of data and materials}

The datasets used and/or analysed during the current study are available from the corresponding author on reasonable request. 


\section{Declarations}

Ethics approval and consent to participate

Not applicable.

\section{Consent for publication}

Not applicable.

\section{Competing interests}

None.

\section{Author details}

'Medical School, College of Medicine and Health, University of Exeter, Exeter, UK. ${ }^{2}$ Department of Engineering, College of Engineering, Mathematics, and Physical Sciences, University of Exeter, Exeter, UK.

Received: 25 June 2021 Accepted: 24 September 2021

Published online: 12 October 2021

\section{References}

1. Judge A, Welton NJ, Sandhu J, Ben-Shlomo Y. Equity in access to total joint replacement of the hip and knee in England: cross sectional study. BMJ. 2010;341:c4092. https://doi.org/10.1136/bmj.c4092.

2. Neuburger J, Hutchings A, Allwood D, Black N, van der Meulen JH. Sociodemographic differences in the severity and duration of disease amongst patients undergoing hip or knee replacement surgery. J Public Health. 2012;34(3):421-9. https://doi.org/10.1093/pubmed/fdr119.

3. Titmuss RM. Commitment to welfare. New York: Pantheon Books; 1968.

4. Smith MC, Ben-Shlomo Y, Dieppe P, Beswick AD, Adebajo AO, Wilkinson $J M$, et al. Rates of hip and knee joint replacement amongst different ethnic groups in England: an analysis of National Joint Registry data. Osteoarthr Cartil. 2017;25(4):448-54 https://doi.org/10.1016/j.joca. 2016.12.030.

5. Chauhan A, Walton M, Manias E, Walpola RL, Seale H, Latanik M, et al. The safety of health care for ethnic minority patients: a systematic review. Int J Equity Health. 2020;19(1):118. https://doi.org/10.1186/ s12939-020-01223-2.

6. Marmot M, Allen J, Boyce T, Goldblatt P, Morrison J. Health equity in England: the Marmot review 10 years on [internet]. London: Institute of Health Equity; 2020 [Accessed 1 Jun 2021]. 172 p. Available from: https:// www.health.org.uk/sites/default/files/upload/publications/2020/Health\% 20Equity\%20in\%20England_The\%20Marmot\%20Review\%2010\%20Yea rs\%200n_full\%20report.pdf

7. National Joint Registry 17th Annual Report 2020 [Internet]. National Joint Registry; 2020 [Accessed 1 Jun 2021]. Available from: https://reports.njrce ntre.org.uk/Portals/0/PDFdownloads/NJR\%2017th\%20Annual\%20Rep ort\%202020.pdf

8. Fordham R, Skinner J, Wang X, Nolan J. The economic benefit of hip replacement: a 5-year follow-up of costs and outcomes in the Exeter Primary Outcomes Study. BMJ Open 2012;2(3):e000752. https://doi.org/ 10.1136/bmjopen-2011-000752

9. Levy RN, DiGiovanni J, Cohen B. Joint replacement in the elderly patient. In: Rosenthal RA, Zenilman ME, Katlic MR, editors. Principles and practice of geriatric surgery. New York: Springer; 2001. p. 900-20. https://doi.org/ 10.1007/978-1-4757-3432-4_63.

10. Storey A. Living longer: how our population is changing and why it matters [internet]. Office for National Statistics; 2018 [Accessed 14 Apr 2021]. Available from: https://www.ons.gov.uk/peoplepopulationandcommun ity/birthsdeathsandmarriages/ageing/articles/livinglongerhowourpo pulationischangingandwhyitmatters/2018-08-13

11. Culliford D, Maskell J, Judge A, Cooper C, Prieto-Alhambra D, Arden NK. Future projections of total hip and knee arthroplasty in the UK: results from the UK Clinical Practice Research Datalink. Osteoarthritis and Cartilage. 2015;23(4):594-600. https://doi.org/10.1016/j.joca.2014. 12.022 .

12. Rheumatology TL. Too long to wait: the impact of COVID-19 on elective surgery. The Lancet Rheumatology.2021;3(2):e83. https://doi.org/10.1016/ S2665-9913(21)00001-1.
13. Dyson M. Budget 2021: What you need to know [internet]. The British Medical Association is the trade union and professional body for doctors in the UK. [Accessed 14 Apr 2021]. Available from: https://www. bma.org.uk/advice-and-support/nhs-delivery-and-workforce/funding/ budget-2021-what-you-need-to-know

14. Mújica-Mota RE, Watson LK, Tarricone R, Jäger M. Cost-effectiveness of timely versus delayed primary total hip replacement in Germany: A social health insurance perspective. Orthop Rev (Pavia). 2017;9(3). https://doi. org/10.4081/or.2017.7161.

15. Sharma A, Kudesia P, Shi Q, Gandhi R. Anxiety and depression in patients with osteoarthritis: impact and management challenges. Open Access Rheumatol. 2016:8:103-13 https://doi.org/10.2147/OARRR.S93516.

16. Inacio MCS, Hansen C, Pratt NL, Graves SE, Roughead EE. Risk factors for persistent and new chronic opioid use in patients undergoing total hip arthroplasty: a retrospective cohort study. BMJ Open. 2016;6(4):e010664. https://doi.org/10.1136/bmjopen-2015-010664.

17. Stronger NHS Action on health inequalities [internet]. NHS Long Term Plan [Accessed 14 Apr 2021]. Available from: https://www.longtermplan. nhs.uk/online-version/chapter-2-more-nhs-action-on-prevention-andhealth-inequalities/stronger-nhs-action-on-health-inequalities/

18. Mason T, Lau Y-S, Sutton M. Is the distribution of care quality provided under pay-for-performance equitable? Evidence from the Advancing Quality programme in England. International Journal for Equity in Health.2016;15(1):156. https://doi.org/10.1186/ s12939-016-0434-5.

19. Chang W-C, Fraser JH. Cooperate! A paradigm shift for health equity. International Journal for Equity in Health. 2017;16(1):12. https://doi.org/ 10.1186/s12939-016-0508-4

20. Cookson R, Propper C, Asaria M, Raine R. Socio-economic inequalities in health Care in England. Fisc Stud. 2016;37(3-4):371-403 https://doi.org/ 10.1111/j.1475-5890.2016.12109.

21. Judge A. Developing methods to investigate equity in access to healthcare using routine data sources: a case study using total joint replacement of the hip and knee [Internet] [PhD thesis]. University of Bristol; 2008 [Accessed 14 Apr 2021]. Available from: https://research-infor mation.bris.ac.uk/en/studentTheses/developing-methods-to-investigateequity-in-access-to-healthcare-

22. Munn Z, Stern C, Aromataris E, Lockwood C, Jordan Z. What kind of systematic review should I conduct? A proposed typology and guidance for systematic reviewers in the medical and health sciences. BMC Med Res Metho 2018;18. https://doi.org/10.1186/s12874-017-0468-4.

23. Page MJ, McKenzie JE, Bossuyt PM, Boutron I, Hoffmann TC, Mulrow CD, et al. The PRISMA 2020 statement: an updated guideline for reporting systematic reviews. BMJ.2021;372:n71. https://doi.org/10. 1136/bmj.n71.

24. Ouzzani M, Hammady H, Fedorowicz Z, Elmagarmid A. Rayyan—a web and mobile app for systematic reviews. Systematic Reviews.2016;5(1):210 https://doi.org/10.1186/s13643-016-0384-4

25. Mújica Mota RE, Tarricone R, Ciani O, Bridges JF, Drummond M. Determinants of demand for total hip and knee arthroplasty: a systematic literature review. BMC Health Services Research.2012;12(1):225. https:// doi.org/10.1186/1472-6963-12-225.

26. Lu CY. Observational studies: a review of study designs, challenges and strategies to reduce confounding. Int J Clin Pract. 2009;63(5):691-7 https://doi.org/10.1111/j.1742-1241.2009.02056.x.

27. Cooper ZN, McGuire A, Jones S, Grand JL. Equity, waiting times, and NHS reforms: retrospective study. BMJ 2009;339. https://doi.org/10. 1136/bmj.b3264.

28. Hollowell J, Grocott MPW, Hardy R, Haddad FS, Mythen MG, Raine R. Major elective joint replacement surgery: socioeconomic variations in surgical risk, postoperative morbidity and length of stay. J Eval Clin Pract. 2010;16(3):529-38 https://doi.org/10.1111/j.1365-2753.2009. 01154.x.

29. Soljak M, Browne J, Lewsey J, Black N. Is there an association between deprivation and pre-operative disease severity? A cross-sectional study of patient-reported health status. International Journal for Quality in Health Care. 2009;21(5):311-5. https://doi.org/10.1093/intqhc/mzp033.

30. Laudicella M, Siciliani L, Cookson R. Waiting times and socioeconomic status: Evidence from England. Soc Sci Med. 2012;74(9):1331-41. https:// doi.org/10.1016/j.socscimed.2011.12.049. 
31. Cookson R, Dusheiko M, Hardman G. Socioeconomic inequality in small area use of elective total hip replacement in the English National Health Service in 1991 and 2001. J Health Serv Res Policy. 2007;12(1_suppl):10-7. https://doi.org/10.1258/135581907780318365.

32. Judge A, Welton NJ, Sandhu J, Ben-Shlomo Y. Geographical variation in the provision of elective primary hip and knee replacement: the role of socio-demographic, hospital and distance variables.J Public Health 2009;31(3):413-22. https://doi.org/10.1093/pubmed/fdp061.

33. Neuburger J, Hutchings $A$, Black N, van der Meulen JH. Socioeconomic differences in patient-reported outcomes after a hip or knee replacement in the English National Health Service. J Public Health. 2013;35(1):115-24. https://doi.org/10.1093/pubmed/fds048.

34. Judge A, Welton NJ, Sandhu J, Ben-Shlomo Y. Modeling the need for hip and knee replacement surgery. Part 1. A two-stage cross-cohort approach. Arthritis Care Research. 2009;61(12):1657-66 https://doi.org/ 10.1002/art.24892.

35. Cookson R, Gutacker N, Garcia-Armesto S, Angulo-Pueyo E, Christiansen $\mathrm{T}$, Bloor $\mathrm{K}$, et al. Socioeconomic inequality in hip replacement in four European countries from 2002 to 2009-area-level analysis of hospital data. Eur J Public Health. 2015;25(suppl_1):21-7. https://doi.org/10.1093/ eurpub/cku220.

36. Kirkwood G, Pollock AM, Howie C, Wild S. NHS Scotland reduces the postcode lottery for hip arthroplasty: an ecological study of the impact of waiting time initiatives. J R Soc Med. 2014;107(6):237-45 https://doi.org/ $10.1177 / 0141076814523950$.

37. Jenkins PJ, Perry PRW, Yew Ng C, Ballantyne JA. Deprivation influences the functional outcome from total hip arthroplasty. Surgeon. 2009;7(6):351-6 https://doi.org/10.1016/S1479-666X(09)80109-1.

38. Cookson R, Laudicella M. Do the poor cost much more? The relationship between small area income deprivation and length of stay for elective hip replacement in the English NHS from 2001 to 2008. Soc Sci Med. 2011;72(2):173-84. https://doi.org/10.1016/j.socscimed.2010.11.001.

39. Clement ND, Muzammil A, MacDonald D, Howie CR, Biant LC. Socioeconomic status affects the early outcome of total hip replacement. J Bone Joint Surg Brit Vol 2011;93-B(4):464-9. https://doi.org/10.1302/0301-620X. 93B4.25717.

40. Keurentjes JC, Blane D, Bartley M, Keurentjes JJB, Fiocco M, Nelissen RG. Socio-Economic Position Has No Effect on Improvement in HealthRelated Quality of Life and Patient Satisfaction in Total Hip and Knee Replacement: A Cohort Study. PLOS ONE. 2013;8(3):e56785. https://doi. org/10.1371/journal.pone.0056785.

41. Weiss RJ, Kärrholm J, Rolfson O, Hailer NP. Increased early mortality and morbidity after total hip arthroplasty in patients with socioeconomic disadvantage: a report from the Swedish Hip Arthroplasty Register. Acta Orthopaedica. 2019;90(3):264-9. https://doi.org/10.1080/17453674.2019.1598710.

42. Darin-Mattsson A, Fors S, Kåreholt I. Different indicators of socioeconomic status and their relative importance as determinants of health in old age. International Journal for Equity in Health. 2017;16(1):173. https://doi.org/ 10.1186/s12939-017-0670-3.

43. Arthritis Foundation. Osteoarthritis [Internet]. [Accessed 10 Apr 2021]. Available from: https://www.arthritis.org/diseases/osteoarthritis

44. Dymond-Green N. How can we calculate levels of deprivation or poverty in the UK? (part 1) [internet]. Data Impact Blog 2020 [Accessed 10 Apr 2021]. Available from: http://blog.ukdataservice.ac.uk/deprived-or-live-inpoverty-1/

45. Employment rate $65+$ People - Office for National Statistics [Internet]. [Accessed 10 Apr 2021]. Available from: https://www.ons.gov.uk/emplo ymentandlabourmarket/peopleinwork/employmentandemployeetypes/ timeseries//fk6/lms

46. Grundy E. The socioeconomic status of older adults: How should we measure it in studies of health inequalities? J Epidemiol Commun Health.2001;55(12):895-904. https://doi.org/10.1136/jech.55.12.895.

47. Thirukumaran CP, Cai X, Glance LG, Kim Y, Ricciardi BF, Fiscella KA, et al. Geographic Variation and Disparities in Total Joint Replacement Use for Medicare Beneficiaries: 2009 to 2017. JBJS. 2020;102(24):2120-8. https:// doi.org/10.2106/JBJS.20.00246.

48. Goodman SM, Mehta B, Zhang M, Szymonifka J, Nguyen JT, Lee L, et al. Disparities in Total Hip Arthroplasty Outcomes: Census Tract Data Show Interactions Between Race and Community Deprivation. J Am Acad Orthop Surg. 2018;26(21):e457-64. https://doi.org/10.5435/ JAAOS-D-17-00393.
49. Beard DJ, Harris K, Dawson J, Doll H, Murray DW, Carr AJ, et al. Meaningful changes for the Oxford hip and knee scores after joint replacement surgery. J Clin Epidemiol. 2015;68(1):73-9 https://doi.org/10.1016/j.jclin epi.2014.08.009.

50. Saunders CL, Abel GA, Turabi AE, Ahmed F, Lyratzopoulos G. Accuracy of routinely recorded ethnic group information compared with selfreported ethnicity: evidence from the English Cancer Patient Experience survey. BMJ Open. 2013;3(6):e002882. https://doi.org/10.1136/bmjop en-2013-002882.

51. Dranove D. Practical regression: fixed effects models [internet]. Northwestern Univesity; 2012 [Accessed 6 Jun 2021]. Available from: https:// canvas.northwestern.edu/files/1812456/download?download_frd=1\& verifier=wrroazw7eYoNieV6SIOFhyVzkbqat1iPWvK4dOHk

52. Gunasekara Fl, Richardson K, Carter K, Blakely T. Fixed effects analysis of repeated measures data. Int J Epidemiol. 2014;43(1):264-9. https://doi. org/10.1093/ije/dyt221.

53. Pardo-Crespo MR, Narla NP, Williams AR, Beebe TJ, Sloan J, Yawn BP, et al. Comparison of individual-level versus area-level socioeconomic measures in assessing health outcomes of children in Olmsted County, Minnesota. J Epidemiol Community Health. 2013;67(4):305-10 https:// doi.org/10.1136/jech-2012-201742.

54. Department for Work and Pensions. New poverty statistics developed to help government target support [Internet]. GOV.UK. [Accessed 12 Apr 2021]. Available from: https://www.gov.uk/government/news/new-pover ty-statistics-developed-to-help-government-target-support

55. The House of Commons Select Committee. Independent Sector Treatment Centres: Fourth Report of Session 2005-06 [Internet]. The House of Commons; 2006 [Accessed 14 Apr 2021]. Available from: https:// publications.parliament.uk/pa/cm200506/cmselect/cmhealth/934/ 934i.pdf

56. Stoye G. Recent trends in independent sector provision of NHS-funded elective hospital care in England [internet]. 2019 Nov [Accessed 10 Apr 2021]. Available from: https://www.ffs.org.uk/publications/14593https:// doi.org/10.1920/BN.IFS.2019.BN0268

57. Kirkwood G, Pollock AM. Patient choice and private provision decreased public provision and increased inequalities in Scotland: a case study of elective hip arthroplasty. J Public Health 2017;39(3):593-600. https://doi. org/10.1093/pubmed/fdw060.

58. Calovski V, Calnan M. Chapter seven: creeping privatisation? Examining procurement choices in the 'new' NHS in England. In: Collyer F, Willis K, editors. Navigating private and public healthcare: experiences of patients, doctors and policy-makers [internet]. Singapore: springer; 2020 [accessed 15 Apr 2021]. p. 131-54. Available from: https://doi.org/10.1007/978-98132-9208-6_7https://doi.org/10.1007/978-981-32-9208-6_7.

59. Pillutla V, Maslen H, Savulescu J. Rationing elective surgery for smokers and obese patients: responsibility or prognosis? BMC Med Ethics. 2018;19. https://doi.org/10.1186/s12910-018-0272-7.

60. Podmore B, Hutchings A, Durand M-A, Robson J, Konan S, van der Meulen J, et al. Comorbidities and the referral pathway to access joint replacement surgery: an exploratory qualitative study. BMC Health Services Research. 2018;18(1):754. https://doi.org/10.1186/ s12913-018-3565-0.

61. LiW, Ayers DC, Lewis CG, Bowen TR, Allison JJ, Franklin PD. Functional Gain and Pain Relief After Total Joint Replacement According to Obesity Status. J Bone Joint Surg Am. 2017;99(14):1183-9. https://doi.org/10. 2106/JBJS.16.00960.

62. Matharu GS, Mouchti S, Twigg S, Delmestri A, Murray DW, Judge A, et al. The effect of smoking on outcomes following primary total hip and knee arthroplasty: a population-based cohort study of 117,024 patients. Acta Orthopaedica. 2019;90(6):559-67. https://doi.org/10.1080/17453674. 2019.1649510.

63. Hutchings A, Neuburger J, Grosse Frie K, Black N, van der Meulen $J$. Factors associated with non-response in routine use of patient reported outcome measures after elective surgery in England. Health and Quality of Life Outcomes. 2012;10(1):34. https://doi.org/10.1186/ 1477-7525-10-34.

64. Achten J, Parsons NR, Edlin RP, Griffin DR, Costa ML. A randomised controlled trial of total hip arthroplasty versus resurfacing arthroplasty in the treatment of young patients with arthritis of the hip joint. BMC Musculoskeletal Disorders.2010;11(1):8. https://doi.org/10.1186/ 1471-2474-11-8. 
65. Ayiku L, Levay P, Hudson T, Craven J, Barrett E, Finnegan A, et al. The medline UK filter: development and validation of a geographic search filter to retrieve research about the UK from OVID medline. Health Information Libraries J. 2017;34(3):200-16 https://doi.org/10.1111/hir. 12187.

66. Hoffman KM, Trawalter S, Axt JR, Oliver MN. Racial bias in pain assessment and treatment recommendations, and false beliefs about biological differences between blacks and whites. Proc Natl Acad Sci U S A 2016;113(16):4296-301. https://doi.org/10.1073/pnas.1516047113.

\section{Publisher's Note}

Springer Nature remains neutral with regard to jurisdictional claims in published maps and institutional affiliations.
Ready to submit your research? Choose BMC and benefit from:

- fast, convenient online submission

- thorough peer review by experienced researchers in your field

- rapid publication on acceptance

- support for research data, including large and complex data types

- gold Open Access which fosters wider collaboration and increased citations

- maximum visibility for your research: over $100 \mathrm{M}$ website views per year

At BMC, research is always in progress.

Learn more biomedcentral.com/submissions 